\title{
RELIGION ET POLITIQUE
}

La Paix. Introd., choix de textes, comment., vade-mecum et bibliogr. par Mai LeQuan. Paris, Flammarion, 1998. 10,8 × 17,8, 253 p., bibliogr. (GF-Corpus).

Le dernier opus en date de la collection «Corpus » éditée par Garnier-Flammarion se présente, comme ses prédécesseurs, sous la forme d'une anthologie de textes philosophiques rassemblés en vertu de leur commun pouvoir d'élucidation d'un concept fédérateur. Constitué suivant une perspective diachronique (les auteurs représentés vont d'Héraclite à Habermas), l'ensemble des extraits en question est précédé d'une introduction synthétique d'une trentaine de pages et suivi d'une brève présentation explicative de certaines notions-clés rencontrées dans les œuvres abordées ou susceptibles d'en affiner la compréhension, les entrées les plus classiques ( « Souveraineté », « Cosmopolitisme », « Droit naturel »...) figurant aux côtés de termes plus inhabituels tels "Agonistique », «Joute», ou encore «Ataraxie ». Exception faite d'un cas isolé de formulation inutilement ambiguë (l'emploi malencontreux de l'expression «droit du sol» dans l'entrée «Nation», p. 229), ce «vade-mecum» constitue un instrument pédagogique de grande qualité. Outre l'introduction générale, l'ouvrage comprend également un commentaire succinct de chacun des textes choisis, ainsi qu'une précieuse bibliographie complémentaire. Il est organisé en trois parties intitulées «Le rapport de la guerre à la paix », «Qu'est-ce que la paix idéale? » et «Le pacifisme juridique ou la paix par le droit».

Ce découpage thématique a pour effet de mettre d'emblée en évidence l'un des principaux traits distinctifs de la démarche adoptée par Mai Lequan, soit le refus d'une approche réductionniste qui n'appréhenderait la paix que dans sa relativité, à travers l'opposition binaire qui la lie au pôle conceptuel opposé qu'est la guerre. La dévolution du traitement de ce dernier aspect à une et une seule des trois parties indique bien que le pari ici engagé consiste au contraire à penser la paix indépendamment de cette dichotomie structurante, comme un objet doté d'une relative autonomie et pourvu de déterminations positives que l'analyste aurait pour mission de dégager.

Les diverses facettes du rapport dialectique entre guerre et paix ne sont toutefois pas négligées : l'ouvrage rend ainsi compte de l'opposition entre les auteurs qui 
mettent l'accent sur la propension belliqueuse de la nature humaine (Machiavel, Nietzsche) et les tenants de la primauté ontologique, et morale de la paix, érigée en valeur suprême (saint Augustin, Érasme), en soulignant que, pour ces irénistes, la paix est la précondition dont dépend la valeur effective de l'ensemble des biens désirables et constitue tout à la fois la finalité naturelle de la guerre (en tant qu'état projeté) et son milieu englobant, l'arrière-fond par rapport auquel celle-ci apparaît comme un phénomène distinct et significatif : "Ainsi donc, comme il y a vie sans douleur et qu'il ne peut y avoir de douleur sans vie, de même il y a paix sans guerre, mais il ne peut y avoir guerre sans une sorte de paix, non pas en tant que la guerre est guerre, mais en tant qu'elle a pour acteurs ou pour théâtre certains êtres, certaines natures qui ne seraient nullement, qui ne sauraient subsister sans une paix quelconque [...] » (saint Augustin, cité p. 99-100). Cependant, dans une perspective stratégique, la pérennisation de la paix en tant qu'état actualisé nécessite vraisemblablement l'acceptation par les acteurs en présence de l'éventualité de la guerre, la non-prise en compte du risque permanent de l'occurrence d'un conflit armé, irréductible car induit simplement par la coexistence d'une pluralité d'entités politiques souveraines non nécessairement unanimes (Hegel, p. 134; Aron, p. 199), pouvant avoir pour conséquence d'en précipiter l'avènement (p. 21, 184). La guerre demeurerait donc en définitive l'horizon indépassable de la paix, et vice versa.

Mais l'auteur prend le contre-pied de la tradition hobbésienne et clausewitzienne : cette dernière réduit implicitement la paix à la désignation de tout état consécutif à la cessation d'un affrontement armé et tendrait ainsi à opérer un amalgame entre celle-ci et les notions voisines de «trêve » et d' " armistice », situées sur un continuum mais différenciées quant à la durée (limitée ou théoriquement illimitée) de la suspension des hostilités et le contenu des anticipations et orientations présumées des protagonistes concernant la tournure des événements futurs (p. 21, 215). Lequan refuse donc de s'en tenir à cette division simplificatrice de l'espace qualitatif des modalités de relation entre États. L'emploi du terme «paix» pour qualifier l'ensemble des situations de non-guerre relèverait selon elle d'un usage langagier abusif vis-à-vis duquel l'analyse conceptuelle serait tenue de prendre ses distances, une approche plus rigoureuse conduisant à mettre en évidence au moins quatre prédicats consubstantiels au noyau sémantique de l'idée de paix :

$1^{\circ}$ Une dimension normative, qui se traduit par l'établissement d'une relation d'ordre juridique, «l'essence de la paix ne [pouvant] apparaître à la simple lumière de l'expérience » (p. 12).

$2^{\circ}$ Le maintien d'un degré minimal d'altérité : la paix présuppose la reconnaissance de certaines différences persistantes entre les instances considérées, non leur éradication. Elle exclut toute exigence d'identité absolue. À cet égard, l'asymétrie observable entre les deux actes de discours que sont la déclaration de guerre et la déclaration de paix est significative : alors que la première est de nature performative, la paix ne saurait en revanche être établie par le seul effet d'une proclamation unilatérale; sur le plan formel, son avènement requiert la conclusion d'un accord posant «une réciprocité des volontés » (p. 13) et, par implication, la pluralité de celles-ci. De manière analogue, à l'intérieur d'une même entité politique, la notion de paix civile fait évidemment référence non à la suppression des conflits mais à leur intégration dans un ordonnancement juridique, à leur institutionnalisation au moyen d'un système de procédures préétablies à fonction canalisatrice. 
$3^{\circ}$ Une dimension volontariste : loin de se réduire à un état de passivité et de relâchement, la paix doit être envisagée comme le produit d'une activité d'institution, sa continuité temporelle ne pouvant être obtenue qu'au moyen d'un processus de pacification toujours renouvelé au sein de la collectivité de référence. De manière générale, elle "présuppose ou instaure une communauté d'action réciproque entre les hommes » (p. 13). Comme le montre Rousseau, la paix, au même titre que la guerre, ne peut donc se concevoir que dans un contexte de socialisation, en raison de la persévérance des sujets en présence dans une modalité déterminée de relation qu'elle implique, qui fait défaut dans l'état de nature. Ce qui nous amène à la quatrième et dernière de ses caractéristiques :

$4^{\circ}$ Une durée en principe illimitée : de Kant à Derrida, nombreux sont les auteurs qui soulignent l'exigence de pérennité inhérente au concept même de paix, la notion de «paix perpétuelle » apparaissant ainsi quasiment pléonastique.

La conjonction de ces quatre attributs essentiels conduit ainsi Lequan à définir la paix comme «un état durable institué volontairement par différentes personnes au moyen d'un contrat éthico-juridique » (p. 13).

Reste alors à examiner les modèles concurrents ayant pour objectif de garantir effectivement la permanence de la paix entre les États. L'auteur s'attache ici en particulier à la perspective kantienne, qui fait l'objet d'une présentation fine et nuancée, mais ce au prix d'un traitement quelque peu expéditif (p. 40-41 notamment) de la position adverse défendue par les tenants de la politique de l'équilibre et d'une approche dite « réaliste» des relations internationales, incarnée notamment par des auteurs néo-hobbésiens extérieurs à la discipline philosophique tels Hans Morgenthau et Kenneth Waltz. Elle met l'accent à juste titre sur le rôle joué par l'analogie établie entre les modalités d'institution de la paix civile et de la paix «cosmopolitique » dans l'élaboration du projet kantien d'Union entre les États, ainsi que sur les hésitations de Kant concernant la forme institutionnelle à donner à celle-ci (confédération horizontale à fonction coordinatrice rassemblant des entités politiques dont la souveraineté demeurerait essentiellement inentamée ou structure fédérale à caractère vertical pourvu d'un degré d'intégration supérieur). Enfin, Lequan entreprend également l'analyse de la notion de «paix intérieure» (p. 29-38), qui désigne «un double mouvement de retrait en soi et d'accueil d'une vérité incommensurable, de repli et d'ouverture au verbe divin [...], [une] force centripète opposée à la force centrifuge qu'exercent les passions » (p. 31), pour aboutir à la conclusion que l'expression en question, tout comme celle de "paix perpétuelle » précédemment évoquée, s'apparente en réalité à un pléonasme : c'est en effet dans ce mouvement d'intériorisation que résiderait l'essence même de la paix.

Exercice de clarification conceptuelle parfaitement maîtrisé et animé par un souci constant de pédagogie, l'ouvrage apparaît, de manière générale, comme un modèle du genre. L'introduction de Lequan est à ce point dense et rigoureuse qu'elle exerce parfois l'effet paradoxal de faire apparaître les extraits retenus, souvent très brefs du fait des contraintes imparties par le format de l'ouvrage, comme quasiment superflus. Aussi les rares réserves que l'on peut être tenté de formuler ont-elles trait davantage aux contraintes en question qu'à un défaut de conception imputable à l'auteur.

À cet égard, certains partis pris méthodologiques imposés par le principe même de la collection dans laquelle le livre s'inscrit qui tend, par construction, à postuler 
l'unité du concept étudié par-delà la diversité de ses acceptions, appellent néanmoins une remarque spécifique. Le choix préalable d'une approche extensive conduisant à accorder a priori une importance égale aux différents contextes d'occurrence du terme " paix », qui se manifeste notamment par le fait de consacrer près d'un tiers de l'introduction à la notion de "paix intérieure », donne parfois le sentiment que l'analyse conceptuelle à laquelle se livre Lequan est en réalité soustendue par la nécessité perçue de discerner à toute force le substrat ontologique commun, dont l'existence est tenue pour acquise, qui viendrait ainsi justifier l'usage consistant à désigner par le même vocable de «paix » une expérience harmonieuse de nature individuelle et une forme déterminée de rapport entre des entités politiques, en écartant d'emblée l'hypothèse que l'une ne puisse apparaître en définitive que comme une métaphore de l'autre, intrinsèquement dépourvue de valeur conceptuelle, et ce au risque de tomber dans le piège du nominalisme. Si l'auteur inclut à bon escient un texte de Nietzsche particulièrement féroce qui dénonce comme un ennoblissement illusoire le fait de baptiser «paix de l'âme » ce qui ne s'avérerait être en définitive qu'un état de bien-être sensoriel (p. 79-80), la conception même de l'ouvrage reflète le rejet de cette position radicale. Or cette orientation plus ou moins explicite apparaît problématique dans la mesure où Lequan ne s'interdit nullement en d'autres occasions de souligner l'inadéquation des usages de la langue commune (tel celui d'englober par défaut sous la dénomination de "paix» l'ensemble des cas de figure caractérisés par l'absence d'affrontement armé) par rapport à l'essence véritable de la notion employée, qu'une approche philosophique rigoureuse permettrait de dégager : on observe ainsi une asymétrie dans le rapport de l'analyse conceptuelle aux usages langagiers, le critère en fonction duquel l'auteur en vient à opter tantôt pour la déférence aux usages en question (la « paix intérieure » est bien une forme de «paix »), tantôt pour leur remise en cause (la paix ne saurait se réduire à l'absence de guerre) n'apparaissant pas toujours entièrement transparent. En définitive, le choix évoqué semble être déterminé par la logique même du projet éditorial, qui comporte une dimension inévitablement artificielle; c'est bien la figure imposée consistant à isoler la paix comme objet d'analyse autonome qui invite l'auteur à donner au concept en question une extension maximale, ce que Lequan elle-même suggère lucidement dès la première page de l'introduction : c'est parce qu' « il n'y a rien à dire de la paix en tant que telle [...] si la paix n'est que le contraire logique de la guerre » qu'il convient de «faire comme si [la paix] ne s'épuisait pas dans sa relation à la guerre » (souligné par l'auteur). En d'autres termes, la direction privilégiée dans l'analyse conceptuelle, loin d'être le produit exclusif d'une nécessité inhérente à l'enchaînement argumentatif, est partiellement dictée par la donnée externe que constitue le découpage thématique initialement opéré, qui exerce en lui-même des effets d'intellection spécifiques. Dans les limites du genre, l'ouvrage représente, on l'aura compris, une admirable réussite. 
Jean Dagen, Entre Épicure et Vauvenargues. Principes et formes de la pensée morale. Paris, Honoré Champion, 1999. 16,5 × 24, 445 p., index, fig. (Moralia, 1$)$.

Les auteurs de ce volume se proposent d'éclairer la diversité des formes que prend la littérature morale à l'époque classique et néoclassique, et de montrer la non-pertinence de sa réduction au moralisme. Les trois premiers articles analysent le problème du fondement de la morale.

Jean-Charles Darmon met ainsi au jour un rapport spéculaire entre littérature et science expérimentale, à travers la médiation de la revendication de ses droits par l'apparence. L'apparence est en effet un concept dont l'ambivalence apparait chez Gassendi dans la dernière Exercitationes du livre II dans la mesure où l'usage qu'il fait des tropes de la sceptique montre qu'elle est à la fois ce qui détruit tout discours dogmatique sur l'homme et le monde ainsi que tout point de vue unique et unitaire, et ce qui permet de construire un discours expérimental sur ces mêmes objets, ainsi qu' « un protocole de déplacement du point de vue ». L'usage antiaristotélicien de ces tropes met donc à mal le concept de «nature humaine » mais légitime l'efficacité d'une catégorie comme celle de la ressemblance pour la penser. Comment éviter les deux écueils que sont le scepticisme et le dogmatisme? Il s'agit de voir que si l'apparence voile la vérité, la vérité ne se dévoile que par l'apparence. Le dépassement du scepticisme ne peut donc se faire que par la médiation d'une théorie du signe et de son interprétation. Gassendi établit ainsi qu'il y a deux types d'objets (cachés selon les circonstances ou par nature), qui renvoient à deux types de signes (commémoratifs ou indicatifs), lesquels supposent un critère double : les sens et la raison. À partir de là, il est possible de dégager une conception non-cartésienne de la position de l'homme face à la nature dans laquelle «le "faire" est mis à distance au profit du voir ». Cette expérience procure un plaisir contemplatif, « porté par le dialogue entre sens et raison», qui dissipe l'inquiétude de la "volonté de savoir».

Le deuxième article montre que, à la différence de Descartes et de Hobbes, le problème moral est pour Locke celui de la connaissance de la loi morale. La loi qui oblige au respect des préceptes voulus par Dieu (condition de l'harmonie de la communitas humaine) n'étant pas innée, elle ne peut être connue que par la Révélation, puis confirmée par la raison. Or, la raison ne peut démontrer l'existence d'une autre vie (nécessaire pour penser les sanctions de la loi de nature); elle est donc incapable de «connaître la loi de nature en tant que loi ». Locke montrera qu' elle nous est donnée par la double réflexion sur l'action divine et sur le propre «making» humain. La raison trouve donc, mais ne fonde pas. Jean-François Lecoq explique ensuite que l'influence de Locke sur le XvIII ${ }^{\mathrm{e}}$ siècle français a surtout porté sur la question de l'accessibilité de la loi naturelle à la réflexion morale, sur l'importance de l'obligation réciproque comme fondement de la légalité de la loi et sur la critique renouvelée du langage comme condition de l'amélioration de la vie d'une société.

Le dernier article de la section «fondements » repose sur l'analyse du paradoxe selon lequel les Lumières seraient, d'une part, une philosophie morale, et d'autre part, les agents de la destruction de la morale par le biais de sa réduction aux mours. La moralité n'a plus son lieu dans l'expérience intérieure, mais elle se trouve là où le sujet se constitue, c'est-à-dire dans l'expérience extérieure, pratique. Mais alors 
sur quoi fonder la norme? Martin Rueff propose et analyse quatre formules latines pouvant servir de devises à la morale des Lumières. De celles-ci, nous pouvons retenir que la morale des Lumières suppose un usage universel, libre et public de la raison, le sentiment de l'appartenance à l'humanité, la constitution d'une anthropologie qui exclut l'intervention de l'infini dans la définition de l'homme ainsi que la psychologie. Les Lumières refusent qu'un transcendantal fonde la morale, mais se divisent en partisans de la morale de l'intérêt et intuitionnistes d'une part, et philosophie kantienne d'autre part. Ce qu'il faut retenir par-delà ces divergences que l'auteur explique en détail, c'est l'ébranlement du discours moral qui permet paradoxalement de faire de Sade le héros des Lumières. Un autre aspect qu'il faut envisager est celui du rapport de la morale des Lumières et de la liberté politique. La thèse (libérale) des Lumières, qui présente l'individu comme un sujet de droit dont l'autonomie est garantie par l'État, se heurte à la thèse républicaine selon laquelle la politique ne s'occupe pas seulement de permettre aux mœurs de s'installer, mais est l'ordre même des mœurs. À l'idée d'une liberté toute négative, indifférente à la morale des citoyens, qui repose sur un contrôle de l'individu saisi dans toute sa complexité, s'oppose une liberté conçue comme fin, non subordonnée à la protection. Rueff termine son brillant article par la détermination des genres littéraires propres à la psychologie morale (la tragédie), et à l'anthropologie, à savoir le drame dans lequel l'individu est façonné par une expérience ordinaire et non finalisée.

Les deux articles suivants traitent de l'intériorité dans la pensée morale de Pierre Nicole et de Choderlos de Laclos. Béatrice Guion montre d'abord que la pensée morale de Nicole repose sur la théologie puisque les "pensées imperceptibles» ( «actes réflexes »; habitudes; amour-propre) qui régissent le comportement humain ne sont imperceptibles qu'en raison d'un manque d'attention imputable au péché originel. Comme elles ne sont pas inconscientes, l'amour-propre doit se déguiser pour s'accomplir, c'est-à-dire prendre la forme de l'obéissance aux lois. L'individu est donc entièrement responsable à l'égard de ses « mouvements secrets ». L'action morale exige alors nécessairement selon Nicole une prise de conscience ainsi qu'une action correctrice sur soi-même, et ce bien que seule la grâce soit susceptible de modifier l'orientation de la volonté. Le moraliste a donc pour rôle de persuader en profondeur, «d'insinuer la vérité, non seulement sans blesser, mais aussi en procurant du plaisir ». C'est donc par les sentiments imperceptibles qu'il faut combattre les sentiments imperceptibles.

En mêlant le roman par lettres et le roman libertin, Laclos met en ouvre le persiflage (qui se distingue de l'ironie, entre autres choses, par son caractère masqué) de manière magistrale. Celui-ci repose sur le concept de l'homme-machine, dont il faut connaître les règles de fonctionnement si l'on ne veut pas être manipulé et par-là même devenir victime. Mais la connaissance de soi ne suffit pas si elle n'est pas accompagnée d'une parfaite maîtrise et de l'analyse d'autrui. Le persiflage prend une forme virtuose chez Laclos en raison de son intégration dans la forme épistolaire qui suppose deux destinataires : le persiflé et le public qui fait l'apprentissage du libertinage durant sa lecture. Mais comment comprendre la conclusion caricaturale et apparemment moralisante du roman? Élisabeth Bourguinat soutient la thèse que la visée de Laclos est «d'épuiser le libertinage dans un feu d'artifice qui en dégoûterait - même à leur insu — les plus décidés partisans ». 
La troisième partie présente deux formes de la littérature morale : la mise en images du combat spirituel, et les Ana. Dans l'Introduction à la vie dévote de François de Sales, le projet didactique reçoit un caractère éminemment visuel par le biais de la présence d'un bestiaire hiérarchisé, ainsi que d'une instance visuelle et narratrice omnipotente. À cette «rhétorique des peintures» se mêle une rhétorique de l'intrusion qui permet de graver l'image dans le cœur du lecteur. Il s'agit donc de convaincre mais en évitant la fascination par l'image. De la même manière, Francine Wild se demande s'il y a une place pour la réflexion morale (qui relève de l'universel) dans les anecdotes des Ana (qui relèvent de la particularité, de la volonté de collectionner, de la fascination pour l'extraordinaire). Il apparaît que l'anecdote peut être matière à une réflexion plus générale (sa portée morale étant explicitée par l'auteur ou non), car celui dont on parle «porte en lui la forme entière de l'humaine condition ». Il n'en demeure pas moins que le genre anecdotique ne cherche pas d'abord à produire des lois à la manière des sciences, ni de la réflexion.

Les articles de la quatrième partie analysent la théâtralité de la pensée morale, dans les Théâtres et la tragédie lyrique. Anne Larue explique que le théâtre-livre se comprend comme monument en deux sens : soit comme « abrégé construit de l'univers », soit comme mémorial (théâtre des cruautés). Si le Théâtre des martyrs est théâtral au sens où il y a mise en scène du supplice, regards convergents, le Théâtre des cruautés des hérétiques de notre temps s'apparente davantage au mémorial dans la mesure où il n'y a pas d'arrêt sur image, mais compilation, accumulation, absence de regard porté. Le tragique se situe donc dans un dispositif dont le but est de concentrer la cruauté en un point focal, ce dispositif étant particulièrement épuré dans le théâtre d'anatomie lequel montre que « souffrir n'est pas nécessairement tragique, c'est souffrir au centre qui l'est». Dans son article, Camille Guyon-Lecoq s'interroge sur la condamnation de la tragédie lyrique par les moralistes. Cette condamnation morale (inséparable d'une condamnation esthétique) s'explique par l'incompréhension du fait que la nouveauté des moyens implique d'autres fins. La tragédie lyrique, parce qu'elle est chantée, réclame la réhabilitation des passions. L'analyse des sentences dans les tragédies de Fontenelle montre qu'elles appartiennent au genre pédagogique, à défaut d'appartenir à un genre moral. De plus, la musique permet une incarnation des passions que n'autorise pas la déclamation. Le spectacle quant à lui est le lieu où la réalité mécanique du monde devient intelligible, où les oracles sont critiqués dans une perspective rationaliste. La tragédie lyrique n'est vraisemblablement pas un genre moral mais elle mine les valeurs de la morale de la grande tragédie et en propose d'autres qui reconnaissent ses droits à la sensibilité.

La dernière partie est axée sur la dimension sociale de la moralité. David Bensoussan se propose de montrer les ressorts stylistiques de l'invention morale chez Saint-Évremond. L'originalité de celui-ci réside dans le fait qu'il «n'utilise les lieux que pour quitter le terrain de toute topique et gagner celui de l'action » et non pour établir une quelconque théorie. Il ne prescrit à son lecteur aucune règle morale ou stratégie de réussite sociale mais il lui donne les éléments d'une technique d'exis- 
tence individuelle qui s'appuie sur une connaissance de soi et une présence attentive à soi : la raison doit élaborer en image l'idée qui est née de l'impression. Son style est en accord avec sa visée puisqu'il s'agit pour lui de mettre l'écriture à l'écoute «des replis et des retours » de notre âme. Ainsi, le choix minutieux des mots, la place accordée au plaisir du lecteur et de l'auteur, la facilité, le refus du pathos au profit d'une ironie diffuse, caractérisent le style de Saint-Évremond qui fait davantage œuvre de sagesse que de morale. L'analyse de la politique de Vauvenargues par Laurent Bove met au jour une similitude entre la pensée de Vauvenargues et celle de Spinoza. L'un comme l'autre explique l'existence de la société civile par l'impuissance des individus, mais aussi par l'ambition de gloire qui repose sur un conatus mimétique. L'État ne vient pas supprimer les rapports de forces, mais les légalise; en ce sens, l'état social et politique est la continuation de l'état de nature. De plus, Vauvenargues, en établissant que l'exercice de la liberté, favorisé par la république, ouvre la politique et l'histoire à un avenir imprévisible, articule l'éthique à une ontologie du temps qui est sous-tendue par l'idée spinoziste d'une productivité infinie de la vie.

Cécile NicCO

Dominique Iogna-Prat, Ordonner et exclure. Cluny et la société chrétienne face à l'hérésie, au judaïsme et à l'islam, 1000-1150. Paris, Aubier, 1998. $14 \times 22$, 510 p., bibliogr., index (Historique).

Dans ce livre riche et stimulant, Dominique Iogna-Prat nous propose une nouvelle définition de la société chrétienne des $\mathrm{XI}^{\mathrm{e}}-\mathrm{XII}^{\mathrm{e}}$ siècles. Le résultat est à la hauteur de l'ambition.

Le choix de Cluny comme poste d'observation privilégié pour mener à bien cette entreprise ne s'explique pas seulement par la richesse du gisement documentaire clunisien. Le monastère se vit comme un «ersatz de Rome », s'identifie au centre de la chrétienté. L'auteur critique à juste titre l'emploi abusif de «clunisien ». À la suite des historiens de l'école de Münster, il distingue l'Ecclesia cluniacensis de la «nébuleuse » clunisienne. La première est une structure juridique regroupant un ensemble de monastères réformés par Cluny, hiérarchisés (abbayes et prieurés), pour laquelle l'auteur refuse le terme «d'ordre » au moins jusqu'à la fin du XII siècle, c'est-à-dire avant que la papauté n'impose des réformes sur le modèle cistercien, faisant de Cluny, un ensemble d'établissements structurés en provinces avec un chapitre général annuel. Quant à la «nébuleuse » clunisienne, elle désigne tout ce qui n'est pas cistercien, c'est-à-dire le monachisme bénédictin traditionnel et, dans un sens plus restreint, les monastères qui adoptent une liturgie ou une organisation matérielle directement issue de Cluny. À partir de ce(s) centre(s), Iogna-Prat s'interroge sur le sens et l'évolution du concept de chrétienté au cours du «moment grégorien », lorsque l'Église se définit dans un sens institutionnel et spatial, à travers un double mouvement, d'inclusion et d'exclusion (l'auteur préfère le terme d'inclusion à celui d'assimilation car ce mot permet de conserver l'idée d'une pluralité dans la réalisation de l'unité). 
Le mouvement d'inclusion lui-même est double. D'une part, il se réalise par la diffusion, dans l'ensemble de la chrétienté, du «parfum » clunisien par les membres de l'Ordre devenus évêques, cardinaux ou papes (l'auteur insiste peu sur cet aspect, mieux connu). D'autre part, le monastère se veut une «arche de Noé » (p. 60), offrant un refuge aux clercs et aux laïcs repentants, aux moines issus d'autres ordres, aux ermites, aux pauvres, etc.; microcosme de l'humanité qui sera sauvé du Déluge. Dans cet espace intermédiaire, dans cet « entre-deux permettant d'anticiper l'au-delà » (p. 92), les moines clunisiens deviennent des «passeurs ». Le nombre important de laïcs bénéficiaires de prodige dans le De miraculis de Pierre le Vénérable ou la fréquence de l'expression monachus nostri congregationis inscrite dans les nécrologues clunisiens (qui, selon Iogna-Prat, désigne des aristocrates laïques ou ecclésiastiques) exprime ce phénomène d'inclusion.

Mais, comment mieux définir une société qu'en se penchant sur la manière dont celle-ci perçoit ses marges? Comment mieux parvenir à cerner les contours de la chrétienté médiévale qu'en étudiant des ouvrages élaborés pour lutter contre les avatars de l'Antéchrist: hérétiques, juifs ou musulmans? C'est pourquoi Iogna-Prat étudie longuement le phénomène d'exclusion à travers les écrits de Pierre le Vénérable : le Contra Petrobrusianos, l'Adversus Judeos, le Contra sectam Sarracenorum et le De miraculis, ensemble cohérent formant un véritable système de pensée à une époque, postgrégorienne, où l'on entre dans l'âge des grandes synthèses doctrinales.

«Premier traité anti-hérétique rédigé dans l'Occident médiéval» (p. 126), le Contra Petrobrusianos, écrit vers 1139-1140, s'inscrit dans une pastorale antipétrobrusienne bien attestée dans les écrits et l'architecture de Bourgogne, de Languedoc et de Provence. Pierre le Vénérable use d'arguments juridiques, cite les auteurs classiques (Cicéron), se livre à une disputatio caractéristique des milieux scolaires du XII ${ }^{\mathrm{e}}$ siècle (l'abbé de Cluny qualifie lui-même son traité d'epistola disputans). Selon Iogna-Prat, pour combattre l'hérésie, l'abbé de Cluny adopte une démarche exceptionnelle. En effet, si le discours antihérétique d'un Bernard de Clairvaux ne relève que de l'imprécation, dévoilant une hérésie sans contenu, celui de Pierre le Vénérable, en revanche, développe une «argumentation défensive » reposant sur l'idée qu'on ne peut condamner une déviance sans l'avoir au préalable examinée et discutée. Dans les années 1150, on peut encore débattre des idées hérétiques. À partir de la fin du XII e siècle, les défenseurs de l'orthodoxie glissent progressivement du discursif au judiciaire et «l'hérésie ne se discute plus » (p. 152). C'est parce que le système de «l'argumentation défensive » déployée par l'abbé de Cluny est sans avenir que le Contra Petrobrusianos a rencontré une étroite diffusion.

Observons les arguments employés par Pierre le Vénérable pour contrer les affirmations de Pierre de Bruis. Face au rejet du baptême des enfants, l'abbé de Cluny affirme que le premier sacrement est un «rite commandé par la foi des autres » (p. 159). Le Christ sauve tout le monde, y compris les enfants, ou ne sauve personne. Cette logique du tout ou rien permet, au passage, à Iogna-Prat de montrer combien, dans ce système, l'individu est pris dans des réseaux très serrés de liens et de nuancer encore « la découverte de l'individuel » des années 1050-1200. Dans un contexte où l'Ecclesia se définit de plus en plus géographiquement, où s'affinent les conceptions de droit d'asile, d'immunité et d'exemption, Pierre le Vénérable se pose 
aussi, contre les pétrobrusiens, en défenseur des lieux de culte. Dans un contexte de réflexion sur le statut des images, il s'avère également indispensable de défendre la Croix, non pas objet d'horreur pour avoir été le lieu des souffrances du Christ comme le pensent les disciples de Pierre de Bruis, mais signifiant pour lequel on doit la même vénération qu'au signifié, le crucifié. Dans un contexte de débat eucharistique ouvert à partir du milieu du $\mathrm{XI}^{\mathrm{e}}$ siècle par Bérenger de Tours, il est aussi nécessaire de défendre la présence réelle. Enfin, comme l'aide aux défunts est au centre du système clunisien, il est impossible à Pierre le Vénérable de ne pas défendre l'utilité des prières pour les morts. À la suite des travaux de Jean-Pierre Torrell et de Denise Bouthillier, Dominique Iogna-Prat établit un parallèle entre le discours défendu dans le Contra Petrobrusianos et le texte du De miraculis, écrit exactement au même moment. On sait, en effet, combien, dans le recueil de miracles rédigé par l'abbé de Cluny, nombreuses sont les apparitions d'hosties contenant l'enfant-Christ ou de revenants réclamant des suffrages aux vivants.

La société chrétienne ne se définit pas seulement au travers des réactions à l'égard des déviances internes. Elle se délimite également par sa dilatation, par l'extension et l'affrontement face aux deux autres religions du Livre. Dans l'Adversus Judeorum rédigé en 1143-1144, l'abbé de Cluny a abandonné l' «argumentation défensive » utilisée contre les pétrobrusiens au profit de l'imprécation. Cela ne l'empêche pas de se montrer «précurseur » (p. 300) puisque après Pierre Alphonse (juif converti), il tente d'utiliser le Talmud, même si, comme le montre très bien Iogna-Prat, il le fait de manière partielle, sans vraiment comprendre l'œuvre. Si, dans les quatre premiers chapitres de ce traité, Pierre le Vénérable se contente de prouver contre les juifs que le Christ est le fils de Dieu, qu'il est le Messie attendu, par le biais d'arguments théologiques, de citations scripturaires et de miracles, en revanche, dans le cinquième et dernier chapitre du traité, l'abbé de Cluny montre davantage d'agressivité, diabolisant les juifs, taxant leurs croyances de fausses et de ridicules. Il pousse son argumentation à l'extrême, posant la question de l'appartenance des juifs à l'espèce humaine, déniant toute existence sociale à des individus qui refusent de sacrifier, de participer à l'échange nécessaire entre l'ici-bas et l'audelà. Les juifs sont, sous la plume de l'abbé de Cluny, des hommes du passé dont le message est dépassé. Cependant, Pierre le Vénérable ne prône pas d'élimination physique car la présence du juif doit continuer à participer à l'actualité de la Crucifixion et de la Résurrection. Il préfère une conversion forcée ou une réduction à l'état de serf. Comme l'ont déjà montré les travaux de Gavin I. Langmuir, le milieu du XII ${ }^{e}$ siècle représente incontestablement un moment capital du passage de l'antijudaïsme à l'antisémitisme.

À travers le Contra sectam Sarracenorum, Pierre le Vénérable vise une dernière cible : l'Islam. S'inscrivant dans un courant historiographique récent, Iogna-Prat nuance le rôle de Cluny dans le déclenchement des croisades : Pierre le Vénérable reste en retrait par rapport à l'enthousiasme d'un Suger ou d'un Bernard de Clairvaux à l'égard du départ en Terre sainte. L'originalité des attaques de l'abbé de Cluny contre les Sarrasins réside surtout dans le fait qu'il cherche à comprendre le texte de ses adversaires. On sait, en effet, qu'en 1142, à la suite d'une tournée d'inspection dans les monastères clunisiens d'Espagne, prenant conscience de la fascination que la culture arabe exerce sur les clercs chrétiens, il commande une traduction latine du Coran. 
Face à ce travail érudit et intelligent, les critiques ne sont que de pure forme. On peut également être surpris par la grande inégalité des chapitres et des thèmes traités. La partie II sur le Contra Petrobrusianos représente près de la moitié de l'ouvrage (161 pages sur 360). À l'intérieur de chaque partie, on rencontre des chapitres très longs ( 50 pages) et d'autres très courts ( 7 pages) qui sont, en fait, des conclusions (chapitre VIII ou XII), ou une introduction (chapitre IX). On peut aussi nuancer parfois le caractère exceptionnel de Pierre le Vénérable. Ainsi, «l'actualité du déicide » (p. 276) rencontrée sous la plume de ce dernier, dans une lettre de 1135 contre les juifs adressée à Henri de Blois, évêque de Winchester, n'est pas un thème rare et original mais, au contraire, un motif récurrent des années 1130-1140, un des principaux fondements de l'essor de l'antisémitisme.

À travers cet ouvrage, Iogna-Prat aborde de très nombreux courants de pensée de la Renaissance du XII ${ }^{e}$ siècle en les éclairant souvent d'une lumière neuve et originale. Après la lecture d'un tel livre, on ne pourra plus, enseignants et étudiants, expliquer l'œuvre de Pierre le Vénérable sans utiliser cet indispensable et précieux commentaire. Il s'agit incontestablement d'un apport capital à l'élaboration d'une sociologie et d'une anthropologie du christianisme. Pour l'abbé de Cluny, revisité par Dominique Iogna-Prat, l'homme ne peut appartenir à l'humanité (au tout) s'il ne compose pas la société. À cause de leur refus de commémorer et de sacrifier, les disciples de Pierre de Bruis, les juifs et les sarrasins s'excluent des échanges entre l'ici-bas et l'au-delà et ne peuvent participer à la fabrication du lien social.

L'ouvrage de Dominique Iogna-Prat s'achève sur la fin du XII siècle, moment d'essor de l'intolérance dans la société chrétienne de plus en plus mise en ordre. Persécution et diabolisation de l'Autre deviennent des moyens efficaces pour se définir. Au-delà de la manière dont la chrétienté s'est délimitée entre l'an mil et 1150 , la lecture de ce livre est une invitation permanente à nous interroger sur l'identité, l'altérité et, partant, sur l'intolérance.

Didier LETT

Histoire de la pensée politique moderne, 1450-1700. Éd. orig. en langue anglaise sous la dir. de James Henderson Burns, avec la collab. de Mark Goldie, éd. en langue française réalisée par Jacques MéNARd et Claude SutTo. Paris, Presses universitaires de France, 1997. 17,5 × 24, 738 p., bibliogr., index (Leviathan).

Cet ouvrage, issu de la célèbre collection des « Cambridge History » rassemble les contributions des meilleurs spécialistes anglo-saxons de la pensée politique moderne. Si l'on doit se féliciter de sa traduction en français, on peut regretter certaines imperfections dans l'édition: les références aux textes, par exemple, sont presque toujours celles de leurs éditions en anglais, quand bien même il en existe une version française. Il est vrai que l'absence d'harmonisation dans le texte original ne facilitait pas la tâche des traducteurs. Ce défaut complique un peu l'utilisation d'un livre pourtant destiné à être fréquemment consulté. Il est en partie compensé 
par un commode dictionnaire biographique en fin de volume, qui donne pour chaque penseur une courte notice et les références bibliographiques majeures.

Une pensée politique moderne? La cohérence chronologique de l'ouvrage, de «l'humanisme civique » des cités italiennes à John Locke, reflète celle dégagée de longue date par l'historiographie anglo-saxonne, autour de quelques concepts clés comme celui du constitutionnalisme. Ce fil conducteur n'empêche pas l'ouvrage de marquer les ruptures, notamment celle provoquée par l'irruption de l'affrontement confessionnel dans le champ politique, et la permanence des héritages médiévaux, notamment celle d'une pensée scolastique qui n'en finit pas de mourir. L'ouvrage commence ainsi significativement par une partie sur «Renaissance et ContreRenaissance », suivant un concept intéressant qui n'est pas assez exploité dans les diverses contributions. En critiquant le concept «d'humanisme civique » forgé par Hans Baron pour analyser les positions des humanistes républicains florentins, les historiens actuels rendent toute sa complexité à la pensée politique renaissante en Italie. Plus que dans des orientations qui peuvent varier, c'est dans une méthode qu'on la reconnaît: enquête historique critique, souci national et discours de la méthode politique. Machiavel se situe bien dans cette tradition, même s'il marque une rupture profonde en dissociant discours politique et moral. La fin de la république florentine ruine cependant les espoirs d'une pensée politique toujours marquée par le républicanisme. Au-delà des Alpes, l'humanisme se révèle lui aussi très divers, même si une analyse comparative de More et d'Érasme permet de voir que tous deux tentent «d'affirmer le triple idéal utopien d'une république gouvernée rationnellement, organisée constitutionnellement et juste du point de vue social» (p. 116), associant ainsi souci platonicien du gouvernement des sages et exigence évangélique de charité envers les pauvres. Cette conciliation est typique de l'humanisme chrétien, qu'il loue la monarchie ou défende la république, et il survit aux convulsions du siècle jusqu'à inspirer Fénelon. Les anciennes disciplines universitaires n'échappent pas au bouleversement renaissant. C'est le cas du droit, avec l'apparition du «mos gallicus » par opposition aux tenants du droit romain. L'éloge du particularisme national passe par une méthode historique et critique appliquée aux anciennes constitutions juridiques et à la jurisprudence.

Avec les Réformes, la pensée politique doit affronter de nouvelles questions, toutes liées à la construction confessionnelle. Comment concilier affirmation des droits de la conscience religieuse, respect des autorités séculières - qui ne partagent pas toujours votre confession —, nécessité reconnue par tous de punir la dissidence (celle de l'autre bien évidemment)? Luther et après lui Calvin ont tendance à prôner une résistance passive aux autorités persécutrices : refus d'obéir aux ordres qui vont contre les commandements de Dieu, mais en même temps absence de rébellion devant la persécution. La théorie se heurte bien vite aux faits et la résistance active trouve des défenseurs. Le problème est de la justifier en droit : c'est principalement en milieu calviniste que l'on trouve de tels développements, même si Robert N. Kingdon rappelle à juste titre que les luthériens ne prônèrent pas toujours une soumission passive, notamment au moment de la guerre de Smalkalde. Ces réflexions protestantes sur la résistance aux tyrans connaissent leur apogée après la Saint-Barthélemy, avec les monarchomaques. Mais bientôt la perspective d'un roi protestant sur le trône de France inverse le débat et ce sont les catholiques de la Ligue qui défendent le droit à la révolte, contre le loyalisme des royalistes 
« politiques ». La grande différence réside cependant dans le moindre appel chez les catholiques à un droit de la communauté à déposer un souverain tyrannique, et à une insistance sur le pouvoir de l'Église à régenter la sphère politique. Pendant que les frères ennemis justifient tour à tour la révolte contre le tyran, un courant trans- ou a-confessionnel développe l'idée des droits imprescriptibles de la communauté sur ses dirigeants ou plutôt de limites au pouvoir de ces derniers, de «constitutions » s'imposant au souverain. Le « constitutionnalisme » se retrouve en milieu protestant comme catholique. Jean Bodin, en affirmant que la souveraineté est indivisible, ne s'oppose pas autant au constitutionnalisme, ou en tout cas ne défend pas autant l'absolutisme qu'on a bien voulu le dire. Il n'en reste pas moins que ses contradicteurs lui opposent l'exemple des monarchies mixtes. L'insistance de Julian H. Franklin sur cette opposition à Bodin peut être salutaire et compenser un excès inverse bien plus courant en milieu français. Mais elle accentue l'impression générale donnée par l'ouvrage, qui passe parfois un peu vite sur des penseurs «absolutistes » majeurs pour s'attarder sur leurs opposants n'ayant pas toujours eu le même écho de leur temps.

Cette tendance résulte-t-elle d'un « anglocentrisme » ingénument avoué en introduction? Les parties consacrées au XVII ${ }^{\mathrm{e}}$ siècle (absolutisme et révolution, la fin de l'aristotélisme, loi naturelle et utilité) tendent à le prouver, avec un regard parfois exclusivement porté sur l'Angleterre. Le lecteur français y gagnera une connaissance plus approfondie de courants souvent ignorés sur le continent. Ainsi les Niveleurs, trop souvent présentés comme des « démocrates », sont décrits bien plus précisément comme des partisans d'une forme de souveraineté populaire plutôt que de droits inaliénables et égaux des individus. Il n'en reste pas moins qu'une analyse de l'absolutisme qui fait bien plus appel aux auteurs royalistes anglais qu'aux théoriciens français surprend un peu. La révolution anglaise a sans contexte été un laboratoire d'idées politiques sans équivalent dans l'Europe du XvII siècle. On ne peut cependant se limiter à cette vision et oublier toute l'Europe méditerranéenne, pour faire un tableau de " grands penseurs » anglais, ou, au mieux, de l'Europe du Nord. Pas une seule fois par exemple, il n'est fait allusion aux arbitristas espagnols, dont le nombre et l'intérêt ne sont pourtant pas négligeables.

Cette importante réserve faite, il n'en reste pas moins que l'ouvrage dégage des évolutions essentielles. Nourri de la lecture de Tacite et du stoïcisme, le scepticisme remet en cause les fondements de l'aristotélisme politique et notamment sa définition de l'homme comme animal politique et sa conséquence d'un naturalisme éthique un peu naïf. Mais, avec Grotius, la pensée politique s'associe à la révolution scientifique contemporaine et fait «des mathématiques le modèle méthodologique des sciences humaines » (p. 458), déduisant les règles politiques de postulats tirés de la loi naturelle. À des titres divers, les penseurs suivants, Hobbes, Spinoza, Pufendorf et jusqu'à Locke, reprennent cette démarche, même si chacun en tire des conséquences bien diverses. La réflexion sur l'État échappe ainsi aux déterminismes religieux du siècle précédent et les spéculations sur le contrat social originel évacuent toutes Dieu, soit réduit au simple rôle de garant rationnel de la vie en société, soit remplacé directement ou indirectement par l'État - monarchique, représentatif, absolu, soumis à la coutume - pour définir le juste et l'injuste. L'ouvrage se garde bien cependant de toute simplification : la sécularisation de la pensée politique se nourrit de bien d'éléments anciens, voire de l'ancienne scolastique; la question reli- 
gieuse est loin d'avoir disparu des préoccupations de nos auteurs. Il n'est donc pas question de présenter l'évolution de la pensée politique moderne comme un chemin triomphant vers l'État sécularisé et sinon déjà démocratique, du moins soucieux de respecter certains droits. Encore au XVIII ${ }^{\mathrm{e}}$ siècle, la pensée politique reste largement conditionnée par des débats anciens et les Lumières s'effrayeront parfois des audaces d'humanistes $d u x^{e}$ ou de monarchomaques du xvI siècle, comme la conclusion le souligne avec humour. Raison de plus pour utiliser cet ouvrage qui, malgré les imperfections relevées plus haut, donne ordre et sens à ce foisonnement intellectuel qui caractérise la pensée politique européenne pendant ces siècles.

Alain TALLON

Jean Nagle, La Civilisation du cœur. Histoire du sentiment politique en France du ХII ${ }^{e}$ au XIX ${ }^{e}$ siècle. Paris, Fayard, 1998. 15 × 23,5, 417 p., ill.

Le projet que Jean Nagle a voulu mener dans ce livre est très ambitieux, puisqu'il a cherché à s'inscrire dans plusieurs courants historiographiques à la fois. Cet ouvrage se situe en effet au croisement de l'histoire de la mort et des rites funéraires, d'une histoire du sentiment politique et d'une histoire de l'amour — l'amour de soi, l'amour de l'autre. Très disparate dans ses présupposés et ses conclusions, cet essai part néanmoins d'une idée assez simple : le XVII siècle français fut une époque au cours de laquelle se produisit l'apogée d'une «civilisation du cœur», dont l'indice le plus évident fut la prolifération des tombeaux de cœur. Certains d'entre eux sont restés célèbres, comme celui qui renferme le cœur d'Henri IV à La Flèche, mais Nagle en a recensé beaucoup d'autres, une centaine environ, qui témoignent de la diffusion de cette pratique au Grand Siècle.

Le rite qui consistait, dans l'aristocratie, à séparer le cœur, les entrailles et le reste du corps, avait commencé à se mettre en place aux XII ${ }^{\mathrm{e}}$ et $\mathrm{XIII}^{\mathrm{e}}$ siècles. En 1299, la papauté tenta pourtant de l'interdire avec la bulle Detestande feriatis, mais bientôt, des exemptions furent accordées aux souverains et aux membres de leur famille. L'enterrement séparé devint ainsi « le signe d'un très haut statut, compte tenu de la rareté du privilège » (p. 142). Les dons de cœur se multiplièrent donc assez facilement, en particulier pour les couvents de Cordeliers, de Jacobins et de Célestins, qui suscitaient une fervente dévotion. De 1361 à 1574, les Valois allèrent même jusqu'à ériger cette pratique en système symbolique, avec la création d'une nécropole des cœurs royaux au couvent des Célestins, à Paris. Ils continuèrent ainsi à inhumer leurs corps à Saint-Denis, pour exalter leurs succès militaires et leur pouvoir de commandement; mais aux Célestins, les tombeaux de cœur furent édifiés pour glorifier «le bon gouvernement et l'essence de la personnalité du prince» (p.90), c'est-à-dire le roi restaurateur des Lettres ou chéri des Grâces.

Utiliser le cœur du prince était donc un instrument politique de premier ordre, tout au moins dans le champ des représentations les plus élaborées du pouvoir royal. Nagle a ainsi cherché à reconstituer un «discours des cœurs », en particulier lors des entrées royales de la fin du Moyen Âge et du début de l'époque moderne. En 
1431, le roi d'Angleterre Henry VI reçut par exemple les cœurs des trois états de la ville de Paris. Ce témoignage de fidélité était très proche des serments médiévaux que s'échangeaient un vassal et son suzerain, mais il annonçait aussi une conception organique du pouvoir qui se développa beaucoup par la suite. $\mathrm{Au} \mathrm{XvI} \mathrm{e}^{\mathrm{e}}$ siècle, les cérémonies, qui visaient à mettre en scène la concorde ou l'unité du royaume pardelà ses différences sociales ou confessionnelles, utilisèrent souvent l'image des cœurs unis. Cette métaphore fut même perfectionnée à l'époque de Louis XIV, avec l'utilisation bien connue du Soleil, à la fois cœur du cosmos, symbole de l'harmonie politique et de la fidélité.

Cette démonstration, qui correspond au « cœur du sujet » de ce livre, est à la fois érudite et claire. Elle se comprend aisément en ayant à l'esprit les travaux de l'école cérémonialiste anglo-saxonne (Ralph E. Giesey et Sarah Hanley entre autres), même si l'on peut toujours douter et débattre à l'infini de la portée réelle que pouvaient avoir des représentations aussi complexes. En fait, le projet de Nagle devient plus difficile à suivre lorsqu'il entreprend une « anthropologie du cœur ». Car le cœur et son image ont investi de nombreux champs de la connaissance, et d'abord, bien sûr, le discours médical. Ainsi, pour les médecins et les philosophes qui s'inspirèrent d'Aristote, au XIII ${ }^{\mathrm{e}}$ siècle, cet organe est-il le «médiateur entre les fonctions hautes et les fonctions basses du corps, élabore-t-il le sang, l'envoie-t-il dans le corps pour le nourrir, et c'est lui qui produit, entretient et diffuse la chaleur dans l'ensemble humain » (p. 46). Ce n'est qu'au début du XvII ${ }^{\mathrm{e}}$ siècle que le cœur perdit ses fonctions nutritives et caloriques: les scientifiques le virent désormais comme une pompe qui ne fut plus considérée comme le séjour des passions humaines.

À partir de ce discours médical, tout un symbolisme fut "greffé » sur le cœur. Dès le $\mathrm{XII}^{\mathrm{e}}$ siècle, la foi et l'hommage, l'amour courtois, le courage et la vaillance chevaleresque furent assimilés au cœur, à un «noble cœur» qui, d'après Nagle, marqua en profondeur la culture nobiliaire de l'Occident. Ce noble cœur était censé se différencier du cœur populaire grâce à sa nature vertueuse, mais aussi par sa nourriture. Pour entretenir sa vigueur, il fallait lui éviter la viande bouillie ou la graisse, et lui fournir plutôt du vin, du vinaigre ou de la viande rôtie, c'est-à-dire des aliments éloignés de l'ordinaire paysan. D'après Nagle, « le chevalier preux se nourrit de la venaison des bêtes qu'il a tuées. Il mange, par un principe de correspondance, pour nourrir son noble cœur, la chair noble des animaux les plus nobles de la Terre » (p. 114).

Selon l'auteur, cette conception du «noble cœur» se diffusa un peu partout jusqu'au XvII siècle, dans des domaines aussi variés que l'imaginaire social, la symbolique politique, l'oraison funèbre ou la tragédie antique ( $L e$ Cid en est l'exemple le plus fameux, mais Nagle étudie également Andromaque). Pourtant, dans le même temps, d'autres conceptions du cœur s'élaborèrent peu à peu, loin de la culture aristocratique. L'idée d'un cœur « sollicité comme intercesseur du monde surnaturel» (p. 160) se développa notamment dans la dévotion populaire : à Poitiers, le 11 septembre, on apportait ainsi des cœurs de cire pendant le pèlerinage de SainteRadegonde. Bien d'autres métaphores du cœur apparurent au cours de la première modernité, en particulier un cœur de la grande robe, propre à exalter la justice des magistrats, ainsi qu'un cœur militaire dégagé de toute connotation nobiliaire, destiné à magnifier le courage des simples soldats sur les champs de bataille. 
C'est ainsi qu'au dernier siècle de l'Ancien Régime, l'image du «noble cœur» fut concurrencée par d'autres systèmes symboliques, et s'en trouva petit à petit désacralisée. À l'époque des Lumières, le mot et le concept continuèrent en effet à exprimer un sentiment politique, mais ils furent surtout utilisés pour critiquer la monarchie, et non pour la glorifier. Mirabeau écrivit par exemple : «Il y a flux et reflux de deux dettes : dette du peuple, dette inverse du Prince [...] Le gouvernement doit sans cesse repousser l'argent aux extrémités de l'État, parce qu'il est de l'essence de la constitution de l'en attirer, ainsi que le cœur repompe et repousse le sang. Si le sang reflue vers le cœur, le désordre se met dans toute la machine » (p. 227). Sous une forme plus radicale, Marat opposa le cœur «criminel» du monarque et le cœur « innocent» du peuple (p. 333). Le « noble cœur» ne survécut finalement, $\mathrm{au} \mathrm{XIX}{ }^{\mathrm{e}}$ siècle, que sous une forme très résiduelle et dépolitisée, avec une nostalgie quelque peu romantique pour le Moyen Âge.

À lire cet ouvrage compliqué, on retire l'idée selon laquelle le cœur était partout : dans l'art statuaire, dans la médecine, dans la tragédie, dans les représentations politiques, dans l'imaginaire social... Partout et nulle part à la fois. Car on trouve de tout dans ce livre touffu : des passages sur l'armée, sur la vénalité des offices, sur l'alimentation, sur les pratiques funéraires... Chaque lecteur, quel qu'il soit, peut donc y retrouver des échos issus de ses propres centres d'intérêts, ou des réminiscences venues d'autres lectures, mais l'ensemble manque d'homogénéité. Peut-être est-ce dû à un plan trop subtil, ou bien à des problèmes de vocabulaire, car on a souvent du mal à savoir de quel «cœur» parle l'auteur (cœur anatomique, noble cœur, cœur populaire...). En outre, Nagle use et abuse des jeux sur le langage et l'étymologie pour réintroduire artificiellement son sujet dans des développements assez convenus. À la page 266, il évoque ainsi «l'écrasement de la discorde » pour décrire les noces du duc de Joyeuse en 1581. Un peu plus loin, il traite de «l'éthique cordiale dans l'ordre somptuaire » pour analyser les rituels du costume... L'auteur s'est enfin laissé aller à des développements trop rapides, sources de jugements à l'emportepièce. On est ainsi surpris de lire, page 301, que « le don lui-même et la libéralité sont en cause » à la fin du XVIII ${ }^{\mathrm{e}}$ siècle. De même, les spécialistes de l'alimentation seront sans doute étonnés d'apprendre que « le paysan ne boit pas de vin. Il n'en a pas les moyens » (p. 111). Mais surtout, pour n'avoir pas clairement délimité son sujet, Nagle a construit un ouvrage qui fait penser aux fameux «trous noirs » qui engloutissent la lumière spatiale sans jamais la réfléchir : un livre sans doute stimulant, mais globalisant, dont l'argumentaire embrasse trop pour, au final, mal étreindre.

Laurent BOURQUIN

Jean-Louis Quantin, Le Rigorisme chrétien. Paris, Cerf, 2001. 12,5 × 19,5, 167 p., bibliogr. (Histoire du christianisme).

Contrairement aux représentations que son titre suggère, ce livre entraîne son lecteur vers une succession de plaisirs. Plaisir d'apprendre, d'abord, car l'auteur 
excelle à faire partager les richesses d'une érudition méthodiquement acquise par la fréquentation d'une foule d'auteurs inconnus ou méconnus. Plaisir de comprendre, ensuite, car, après avoir situé le phénomène dans la longue durée des Réformes catholique et protestante et dans les espaces confessionnels de l'Europe moderne, Jean-Louis Quantin articule avec maitrise différents niveaux de lecture du rigorisme. Éclairci au préalable dans son concept par une étude sémantique, le rigorisme sollicite en premier lieu l'intelligence de ses facteurs théologiques : la nostalgie de la discipline pénitentielle de l'Église ancienne, qui reportait l'absolution jusqu'à l'accomplissement de la pénitence; l'opposition suscitée par la doctrine «probabiliste », inventée par les Dominicains, mais largement appliquée par les Jésuites à la direction des gens du monde; la thèse « contritionniste », interprétant avec un haut niveau d'exigence spirituelle la doctrine tridentine de la justification, impossible à obtenir sans l'amour de Dieu (la thèse « attritionniste » ou minimaliste posait que la crainte du châtiment suffisait à la réception valide de l'absolution). Toutes ces doctrines furent passionnément élaborées ou discutées du concile de Trente au début du XVIII ${ }^{\mathrm{e}}$ siècle.

Elles sortaient des cours de théologie pour déterminer un type de rapport entre Église et société, qui se profile aussi dans l'histoire des protestantismes : en effet, les rigoristes étaient conduits par la force des choses à se constituer en communautés plus ou moins séparées, à l'intérieur d'Églises plus vastes et moins sévères. Fortement enlacée, donc, à l'histoire sociale de l'Occident moderne, l'histoire du rigorisme concerne aussi l'histoire politique. Car le parti rigoriste s'emploie partout à solliciter des pouvoirs d'État l'application de ses consignes de perfection morale. Cela est bien visible dans l'ordre juridique institué par les monarchies catholiques. En milieu protestant, le rigorisme s'imposait inégalement dans les Églises luthériennes et dans les Églises réformées. Le piétisme, si important dans l'histoire de l'Allemagne religieuse, fut une réaction contre l'indulgence des États luthériens envers les chrétiens imparfaits. Dans les Églises réformées, de Genève à la Nouvelle-Angleterre, l'histoire est longue des ordonnances publiques, inspirées de la loi mosaïque, et tendant à réglementer la vie privée. L'inscription des «saints », des godly, dans l'histoire des États-Unis, est encore d'actualité. L'histoire de ces ordonnances ou de leurs parallèles catholiques, débouche finalement dans l'anthropologie historique : il est question du rapport au corps et au sexe, de la place de la fête et de la danse dans la sociabilité "moderne », ou du statut de l'esclave dans la société américaine.

Selon Quantin, le déclin du rigorisme fut moins dû à la réception généralisée de la morale dite «liguorienne » (du nom du rédemptoriste saint Alphonse de Liguori) qu'à un ensemble de décisions romaines destinées à faciliter l'accès à la pénitence et à l'eucharistie. Pour le rigorisme protestant, l'auteur cherche plutôt l'explication dans le relâchement du lien entre Église et société. Il remarque qu'en sollicitant l'appui des pouvoirs publics, les divers rigorismes s'empêtraient dans des contradictions internes, car la ferveur spirituelle ne se nourrit nullement de rites socialement obligatoires. En dépit de ses limites, la réflexion sur la pastorale rigoriste doit mettre à son actif un considérable raffinement de la conscience morale et de l'intériorité spirituelle. En terminant, Quantin note que le regard de l'incroyant occidental considère avec faveur le rigorisme chrétien, qui serait la forme pure du christianisme. Alors ne resterait-il pas à écrire une histoire aussi magistrale, qui serait non celle du 
laxisme, mais celle du pardon, question par ailleurs si vive dans l'interrogation éthique de notre temps?

François LAPLANCHE

Alain TAllon, La France et le concile de Trente (1518-1563). Rome, École française de Rome, 1997. $16 \times 24,5,975$ p.

Le ralliement de la France gallicane à une Réforme catholique dirigée depuis Rome par les papes était moins qu'évident. D'autres solutions auraient été possibles : le basculement de la fille aînée de l'Église dans le camp protestant, ou la constitution d'une Église nationale, sorte de patriarcat gallican. L'étude amplement documentée d'Alain Tallon s'affronte à ce grand problème historique, dont le dénouement a conditionné pour longtemps le sort du catholicisme en Europe. L'auteur a divisé son enquête en trois parties, correspondant à des démarches historiographiques différentes : la première partie relève de l'histoire diplomatique et événementielle, elle retrace, au fil des règnes et des pontificats, les fluctuations de la politique française vis-à-vis de la réunion conciliaire; la deuxième partie appartient à l'histoire des croyances et des doctrines, elle s'intéresse aux conceptions du concile en France; la troisième partie, qui est d'histoire sociale et culturelle, étudie le rôle des évêques au concile de Trente, depuis l'organisation matérielle et les conditions du voyage, jusqu'aux engagements des évêques français dans les décrets tridentins. La démonstration est soutenue par 60 pages d'annexes et 50 pages de « sources et travaux ».

L'auteur considère que la date de 1559 peut être retenue comme une datecharnière. Avant elle, la participation des Français au concile de Trente (à la fois par des ambassadeurs du roi et par des évêques) est coordonnée à une double préoccupation politique : la rivalité avec Charles-Quint impose au roi de France de ne rien faire qui puisse favoriser son rival et donc de s'opposer à la tenue d'une assemblée dont les décisions pourraient pacifier l'Allemagne; à l'intérieur du royaume, le monarque entend rester le chef de l'Église, au temporel, et ne pas se trouver lié par des décrets réformateurs empiétant sur ses privilèges. La participation des évêques français est donc très modeste à la première session du Concile (deux évêques français sur 25 prélats à l'ouverture, à Trente, le 13 décembre 1545), beaucoup plus importante lors de la session conciliaire tenue à Bologne (parce que, pour les besoins de sa politique italienne, Henri II cherche à se rapprocher du pape Paul III). Mais c'est surtout devant la montée de la Réforme dans le royaume et avec le début des guerres de Religion que la France se rallie au Concile. Cependant avec deux visées bien différentes, selon qu'il s'agit de la régente Catherine de Médicis ou du prestigieux cardinal de Lorraine (Charles de Guise). La régente, pour apaiser les chefs du parti protestant, est attachée à la tenue d'un « libre et saint concile », selon la traditionnelle expression gallicane : il se tiendrait hors des territoires d'Empire et accepterait la discussion avec les théologiens protestants. Le Cardinal veut en finir avec l'hérésie et, puisque le colloque de Poissy (1561) a échoué, il faut définir clai- 
rement les positions catholiques, admettre des concessions en matière liturgique et, surtout, s'attaquer à la réforme des abus. En fait, c'est le choix du cardinal qui a prévalu, les évêques français ayant perçu que le dénouement d'une crise religieuse inouïe dépassait les limites de l'initiative royale.

La deuxième partie de l'ouvrage cherche à comprendre comment évolue au $\mathrm{xvI}^{\mathrm{e}}$ siècle le « conciliarisme» français. L'une des «maximes gallicanes » n'est-elle pas la supériorité du concile général sur le pape et la vocation de cette assemblée à réformer la papauté, coupable de tous les maux de l'Église? En saine doctrine gallicane, les Français sont d'entrée de jeu défavorables à un concile convoqué par le pape et dirigé par ses légats. Cependant, l'impasse doctrinale à laquelle aboutit le principe de la sola Scriptura, déjà manifestée par les querelles christologiques de l'Église antique, pousse les évêques et les théologiens français à chercher appui sur la Tradition, dont l'expression la plus autorisée appartient au concile général. Ce ralliement de principe ne rend pas nos Français insensibles aux critiques venues des milieux humanistes et gallicans : qu'est-ce qu'un concile soi-disant général qui rassemble surtout des évêques italiens? comment axer une réforme sur l'action pastorale de l'évêque diocésain sans prendre en considération le vœu gallican de retour aux élections épiscopales et sans aborder le problème du « droit divin » des évêques (ils tiennent leur fonction du sacrement de l'ordre, non de l'autorité du pape)? Ces réserves expliquent qu'en dépit de la circulation dans le royaume des textes tridentins, en traduction française, la Réforme catholique ne s'opère pas toujours en France en référence à eux. Pour Tallon, le ralliement français au Concile exprime le choix du moindre mal. L'université de Paris, comme corps de docteurs, la nation française, comme membre du Corps mystique, n'ont plus le rayonnement de l'époque médiévale (conclusion de la deuxième partie, p. 555-556) et l'Église gallicane, seule, ne peut venir à bout de la crise.

Dans la troisième partie, après une étude historique et sociologique des prélats et théologiens français présents au concile de Trente, Tallon dégage les traits majeurs de leur action dans le milieu conciliaire. Ils se font remarquer par leur souci de présenter la doctrine de façon ferme et claire, de manière à ce que les fidèles puissent être convenablement instruits. Ils insistent sur la responsabilité épiscopale, qui exigerait en principe que la nomination à tous les bénéfices soit réservée à l'évêque diocésain. Ils combattent contre l'exemption des ordres religieux. Ils critiquent durement les exigences insatiables de la fiscalité romaine, qui crée le désordre dans les diocèses par la multiplicité des dispenses et privilèges concédés moyennant argent. En résumé, ils cherchent à garder leur indépendance aussi bien vis-à-vis de la cour de Rome que du roi, dans le respect dû à ces deux autorités. Mais toute idée de concession aux protestants disparaît de leurs interventions, quelles qu'aient été les primitives sympathies humanistes de certains d'entre eux : ils ont perçu la Réforme comme une rupture de l'antique foi du royaume, et l'angoisse devant ce péril poussera même certains d'entre eux à admettre dans leur diocèse des fondations de la Compagnie de Jésus, cette milice du pape au cœur de l'Europe.

Les conclusions de Tallon sont fondées sur une vaste documentation, rigoureusement analysée, et sur la discussion de l'historiographie antérieure (Lucien Romier, Lucien Febvre, Alphonse Dupront, Joseph Lecler). Ramassées dans une « conclusion générale », elles emportent la conviction. Bien qu'il soit acquis que la réforme de l'Église ait été largement entreprise avant le Concile, les décrets de celui-ci ont 
permis l'unification et l'encadrement des efforts réformateurs : de ce point de vue, la participation des Français au Concile marque le net engagement de l'Église gallicane dans la Contre-Réforme, car Tallon n'a pas peur du mot. Ensuite, la volonté des monarques de mener à bien par eux-mêmes la réforme de l'Église, la répugnance des très-chrétiens à recevoir dans le royaume les décrets du Concile soulignent, pour l'auteur, l'archaïsme de leur conception sacrale du pouvoir. En se ralliant à l'assemblée de Trente, les évêques français, à la suite du cardinal de Lorraine marquent de façon très nette la distinction du spirituel et du temporel : il appartient au Concile, non au roi, de dire la foi de l'Église universelle et d'en appliquer les préceptes à la conduite des chrétiens. Toutefois, il ne convient pas d'opposer, de manière frontale, esprit tridentin et fidélité gallicane, car le compromis du cardinal de Lorraine, son engagement dans l'œuvre de Trente laissent intact l'essentiel de l'héritage gallican. Seulement, pour pouvoir rester elle-même, c'est-à-dire catholique, l'Église gallicane a besoin de l'Église universelle (la comparaison s'impose avec la situation actuelle de la France : pour demeurer elle-même, elle favorise la construction européenne, mais non sans nostalgie). Enfin, les Français ont apporté à Trente leur souci de définitions claires, aux corollaires pratiques évidents et leur préférence pour une dévotion pure, sans compromission du sacré et du profane.

L'apport le plus original de l'ouvrage consiste en cette réestimation de la spécificité gallicane, faudrait-il dire de l' «exception française » (tant l'histoire religieuse de l'Europe est la scène de l'histoire politique à venir)? Tallon insiste, nous l'avons dit, sur ce point que la politique religieuse des très-chrétiens, loin d'être «moderne » (avant tout soucieuse des intérêts temporels du royaume) est très précisément «archaïque», bloquée dans une conception sacrale de la fonction royale. Peut-être cette politique fut-elle « séculière » à l'extérieur, « sacrale » à l'intérieur, comme le montrerait encore l'exemple de Louis XIV.

En revanche, l'effort de l'auteur pour dépasser l'opposition humanisme/scolastique dans son jugement sur les débats doctrinaux du concile de Trente semble moins convaincant. Il propose même, pour caractériser la culture des théologiens français, l'expression d' «humanisme scolastique ». Certes, les prélats et les théologiens français à Trente utilisent largement les citations de la Bible et des Pères dans leurs interventions, comme le montrent les études quantitatives de Tallon. Mais ce n'est pas tomber dans l'anachronisme que de constater un hiatus entre les définitions tridentines et les constats de la philologie s'appliquant aux textes bibliques et patristiques : la preuve en est que, devant l'assaut porté par les controversistes protestants contre les certitudes tridentines, l'érudition gallicane admettra qu'il faut se mettre au travail (par exemple, le statut des livres de l'Ancien Testament absents du canon hébreu, définis comme inspirés par les pères de Trente, est loin d'être clair pour l'historien, même au Xvi e siècle, et les remarques d'Érasme sur l'ambiguïté de maint texte scripturaire utilisé par les théologiens restaient solides). La question se pose donc à un niveau plus profond que celui de l'osmose entre deux méthodes chez le même personnage. Il s'agit d'un débat sur l'interprétation des origines chrétiennes, rapidement verrouillé par la raideur de la dogmatique luthérienne ou calviniste, comme par le dédain catholique pour les novatores. Il ne reprendra sur des bases clarifiées qu'au $x^{\mathrm{e}}$ siècle.

François LAPLANCHE 
Port-Royal et l'histoire. Paris, Bibliothèque mazarine, 1998. $16 \times 24,375$ p. (Chroniques de Port-Royal, 46).

Les « Chroniques de Port-Royal » proposent en un seul numéro les communications prononcées lors de deux colloques organisés en 1997, "Port-Royal et l'histoire » et "Jansénisme et conscience nationale». Bernard Chédozeau ouvre les débats par un état des lieux de l'histoire en France au XvII ${ }^{\mathrm{e}}$ siècle : l'histoire, religieuse ou non, a été profondément renouvelée par les changements prodigieux qui suivent le concile de Trente. Peu à peu, dans la mouvance du gallicanisme, on voit apparaître une histoire de France profane qui ignore l'histoire universelle du catholicisme tridentin. Hervé Savon étudie les biographies des Pères de l'Église écrites par l'école de Port-Royal. Il remarque que les Pères choisis s'inscrivent dans les combats du $\mathrm{XVII}^{\mathrm{e}}$ siècle. Ils constituent un modèle de sainteté qui joue un rôle déterminant dans les engagements du présent. Les Pères sélectionnés, si l'on peut dire, ont presque tous en commun d'avoir été, à un moment ou à un autre de leur existence, en opposition au «grand nombre» de l'Église, alors que ce grand nombre était dans l'erreur. La résistance aux ariens vient justifier la lutte contre le molinisme : saint Jean Chrysostome devient l'image même de la sainteté et s'impose avec le combat de Soanen contre le concile d'Embrun (1728). Cet événement marque le début de la publication régulière des Nouvelles ecclésiastiques, et je ne peux que confirmer la présence obsédante du modèle chrysostomien au XVIII ${ }^{\mathrm{e}}$ siècle. Jean-Marc Delabre s'intéresse à Robert Arnauld d'Andilly comme traducteur de Flavius Josèphe: il souligne les aspects mondains du personnage, sa volonté de «plaire au siècle» en se soumettant aux normes stylistiques de son temps et en assurant la promotion de son œuvre. Jean Mesnard s'interroge sur la présence de saint Louis dans la pensée, la spiritualité et dans la vie de Port-Royal. Deux biographies de saint Louis proviennent d'amis de Port-Royal, celle bien connue de Le Nain de Tillemont, et celle bien oubliée de Filleau de La Chaise. Cette dernière est pourtant fondée sur les notes manuscrites de Tillemont. Mais saint Louis apparaît également dans la correspondance que la mère Angélique entretient avec Marie de Gonzague devenue reine de Pologne. La dévotion pour le personnage du saint roi méritait d'être soulignée, elle tient à l'identité même du monastère qui y retrouve ses origines. Mais plus fondamentalement, comme le souligne fort bien Mesnard, elle marque le triomphe de l'association de l'esprit chrétien et de l'esprit français. C'est l'idéal de la perfection dans le monde et dans la gloire, incontestablement la plus difficile à réaliser surtout pour un roi. Saint Louis demeure le prince idéal, celui qui fait preuve d'une sagesse fondée sur la justice, qui mène une politique respectueuse des réalités, mais trouve son plus grand mérite dans le refus du réalisme. À une époque où les éloges de Louis XIV placent le Roi-Soleil au-dessus de tout et de tous, y compris de saint Louis, l'admiration de Port-Royal pour le monarque médiéval qui dure jusqu'à la fin du XvII ${ }^{\mathrm{e}}$ siècle a presque des allures contestataires. Cependant, les historiens de saint Louis selon Port-Royal se révèlent finalement décevants. Le Nain de Tillemont fournit des matériaux pour l'histoire, mais n'écrit pas une histoire proprement dite qui doit aller au-delà des faits; l'entreprise de Filleau de La Chaise n'est pas convaincante : «En définitive, Port-Royal ne devait réussir en histoire qu'en racontant sa propre histoire », conclut Mesnard. À partir du travail de 
«mise en mémoire » entrepris au début des années 1650 par les amis de Port-Royal, Jean Lesaulnier propose une relecture d'un épisode fondamental du mouvement : « la journée du guichet». Il montre comment se compose une narration embellie, transfigurée par le souvenir d'une entreprise difficile devenue un symbole. Lesaulnier s'intéresse encore à toute la production hagiographique de Port-Royal et notamment aux nécrologes qui constituent une source maîtresse qui mériterait une exploitation systématique. Gérard Ferreyrolles revient sur la question de l'histoire chez Pascal : événements de l'histoire, science de l'histoire, sens de l'histoire. Les empires succèdent aux empires car chacun se construit sur les ruines de l'autre, mais au sein de cette universelle instabilité une pérennité se fait jour, celle du peuple juif, les prophéties se réalisent en la personne de Jésus-Christ, et sa mort marque la naissance d'une nouvelle perpétuité, celle de l'Église. Jésus-Christ est le centre de l'histoire, qui est histoire d'une Révélation. Jean-Louis Quantin souligne l'importance des références à l'Église primitive, ainsi que la volonté de retrouver la pureté primitive, et la haine de la «nouveauté » qui marquent le jansénisme entre l'Augustinus et la Perpétuité. Autant de traits de ce que l'on pourrait appeler une « historicisation de la religion ». Les prodiges, la doctrine, la résistance à la persécution sont des signes de la vérité dont l'histoire, dans sa répétition-reproduction du passé donne les clefs. Aux persécutés pour la vérité, Dieu livre parfois la connaissance de l'avenir «pour mieux y retrouver le passé ». Bernard Chédozeau complète cette analyse en démontrant combien le providentialisme des historiens catholiques augustiniens s'inscrit dans une tentative désespérée de récuser les dangers et les progrès de la science chronologique, de refuser l'évolution en valorisant la perpétuité. Nicolas Piqué interroge la distinction du fait et du droit à partir des enjeux historiques qu'elle met en branle. La légitimité de cette distinction délimite et autonomise un champ mondain, celui des affaires humaines. Contrairement à la notion médiévale d'imperium, qui assimile le fait et le droit en faisant «dériver l'organisation de la réalité mondaine du règne divin », Arnauld instaure une rupture dans le domaine politique qui marque une étape dans le processus de laïcisation qui définit la modernité. Christian Nadeau reprend et approfondit les différences entre le Mars gallicus de Jansenius et le non moins célèbre pamphlet de Léonard de Marandé, Les Inconvénients d'État procédant du jansénisme. Alors que pour Jansenius l'autonomie du politique exige le primat du religieux, Marandé illustre le modèle théologico-politique selon lequel la foi constitue le socle des vertus civiques dans une politique elle-même sacralisée. Ghislain Waterlot envisage, à partir des deux avocats Louis-Adrien Le Paige et GabrielNicolas Maultrot, dont les convictions divergent au moment de la constitution civile du clergé, une analyse rétrospective du jansénisme parlementaire du XVIII ${ }^{e}$ siècle.

Deux érudites publications de documents viennent compléter cet ensemble. Jean Lesaulnier présente et commente l'inventaire des livres de l'hôtel de Liancourt. Denis Donetzkoff fait de même pour Les Sentiments et Les Remarques de Martin de Barcos sur l'oraison mentale.

Les différentes communications soulignent l'importance de l'histoire à Port-Royal. Les «amis de la vérité » entretiennent avec le passé une relation privilégiée dans la mesure où ils veulent être perçus comme les adversaires de la nouveauté. Ils souhaitent le retour aux valeurs de ce temps privilégié du passé qu'a été l'Église des premiers siècles. Ils sont les héritiers exclusifs et jaloux de ce temps primordial. C'est bien souvent au nom même de cette fidélité qu'ils s'engagent, comme malgré 
eux, dans les chemins de la contestation et qu'ils inventent des éléments de critique du présent. Parmi d'autres, surtout au XviII ${ }^{\mathrm{e}}$ siècle, ils construisent un passé révolutionnaire.

Monique CotTret

Pierre-François Moreau et Jean Robelin, éd., Langage et pouvoir à l'âge classique. Besançon/Paris, Presses universitaires franc-comtoises/Diff. Belles-Lettres, 2000. 14,7 × 21,7, 266 p. (Annales littéraires, 704, sér. $\mathrm{A} \Gamma \Omega \mathrm{N}, 15$ ).

Ce recueil d'articles met au jour des aspects peu connus des rapports entre langage et pouvoir à l'âge classique : le langage apparaît ainsi comme le pouvoir propre de l'union de l'âme et du corps; mais il est aussi une puissance constitutive de l'espace public et non simple police des âmes par le pouvoir; enfin, la conception dévalorisante du langage subordonné à l'imagination doit être dépassée par la prise en compte de sa puissance symbolique qui permet d'atteindre l'au-delà de la raison humaine. Ce livre s'articule autour de deux thèmes, le premier s'intitulant « Pouvoir du langage, langage du pouvoir », le second «Dire le pouvoir, dire son au-delà ». Dans son article sur le langage politique chez Machiavel, Agnès Cugno s'attache à déterminer qui du pouvoir ou du langage est premier, problème qui engage la vérité même de la politique machiavélienne. L'auteur montre d'abord que le langage est un moyen au service du pouvoir en raison de son caractère dissimulateur, de son pouvoir d'influencer le cours des événements, ainsi que de son pouvoir évocateur. Mais ne peut-on pas penser que c'est parce que la réalité n'existe qu'à travers son interprétation que cette utilisation du langage est possible, auquel cas le langage serait à l'origine du pouvoir et le lieu de ce pouvoir? La vérité du politique apparaît en effet dans le langage, et non dans l'être. Il faut donc renoncer à la problématique morale pour la remplacer par une interrogation métaphysique : «Sous le rapport de l'Être, le prince doit être bon, mais sous celui du Manifesté il doit savoir ne pas l'être, et donc "paraître" bon. » Le langage et le pouvoir forment un chiasme, où ils sont analogiques dans l'Être, et interactifs dans l'apparaître.

Jean Terrel souligne ensuite l'originalité de Hobbes : Le langage comme pouvoir spécifique des hommes est interprété par ce dernier en termes de neutralité éthique : «Le langage ne rend pas l'homme meilleur, mais plus puissant. » La puissance du langage pose des problèmes quand elle prend la forme de la rhétorique comprise comme discours persuasif qui communique des opinions là où il convient d'enseigner la vérité. Terrel insiste sur le fait que l'utilité sociale du langage est inséparable de la fragilité de la convention dont il est la condition. À l'impuissance des paroles, Hobbes oppose ainsi la puissance coercitive du souverain. Pourtant, celle-ci repose elle aussi sur une convention. C'est pourquoi, pour obtenir l'obéissance, l'enseignement qui produit la conviction est plus efficace que la contrainte. Il faut donc penser la possibilité d'une rhétorique de l'autorité qui enveloppe l'évidence de la vérité, laquelle a pour condition la rencontre entre le souverain et la science politique. 
Dans son article, Pierre-François Moreau interroge les rapports du langage et du pouvoir à partir d'une phrase énoncée deux fois dans le Traité théologico-politique : « [...] on ne commande pas aux âmes comme aux langues » (p. 58). À première vue, il n'y aurait pas de pouvoir sur les âmes, celles-ci relevant de la sphère privée, alors qu'au contraire, la langue comme signe du public serait susceptible d'être contrôlée par un pouvoir. Néanmoins, il semble possible de faire des objections à ces arguments : d'une part, les entendements peuvent être subjugués indirectement (certes de manière limitée); d'autre part, si les hommes ne maîtrisent pas toujours leur langage individuellement, a fortiori le souverain rencontrera-t-il des difficultés pour contrôler celui de ses sujets. Il faut donc leur accorder la liberté de parole en la limitant aux discours non séditieux et ce pour les mêmes raisons qu'il est « difficile mais indirectement possible de commander aux âmes » (p. 66).

À partir de l'association établie par Rousseau entre la nature d'un État et le régime linguistique qui lui est contemporain, André Charrak analyse le rôle de l'éloquence dans la constitution d'une communauté affective ainsi que ce que révèle la dégradation de la langue sur le pouvoir politique. L'éloquence manifeste le pouvoir du langage dans sa dimension persuasive. En effet, en persuadant, l'éloquence oblige sans contraindre et marque la présence de la liberté politique. Dans les États despotiques, elle est remplacée par le langage de la force et par l'écriture, lesquels substituent à l'adhésion des cœurs la peur de la puissance exécutive. L'auteur montre ensuite l'influence durable de la langue sur la qualité des mœurs et souligne le consentement de la multitude à sa propre servitude.

Le lien établi par Vico entre trois sortes de natures, trois sortes de langues et trois sortes d'autorité fait l'objet de l'article d'Olivier Remaud. Le $\$ 32$ de la Scienza nuova constate que la question politique naît avec le langage conventionnel, c'est-àdire avec le langage qui ne maintient pas la signification naturelle des mots. La langue humaine s'oppose en cela à la langue muette divine et à la langue emblématique héroïque. Or, à ce changement correspond le passage de la loi d'un état secret à un état public, lequel correspond aussi au passage de l'équité civile (l'autorité n'est exercée que par un petit groupe) à l'équité naturelle (la représentation du pouvoir est librement partagée). Le rythme tertiaire de l'histoire dissimule donc la lutte entre deux natures humaines (les puissants et les faibles) pour l'acquisition de droits. L'analyse de la polysémie du terme «nature » permet ainsi à l'auteur (p. 104) de montrer que l'histoire est «le mouvement d'une hétérogénéité des natures à l'homogénéité d'un droit commun à l'humanité », ce qui suppose l'existence d'un moment où la langue finit par devenir « favorable à la liberté » comme le dit Rousseau.

Colas Duflo étudie le pouvoir créateur du langage tel que l'a révélé Diderot. Il s'agit de voir que le pouvoir du langage suppose comme sa condition le langage du pouvoir au sens où l'effet du performatif linguistique n'est possible que parce qu'il s'appuie sur le pouvoir du législateur qu'il dissimule néanmoins. C'est pourquoi, selon Diderot, le pouvoir ne peut manquer de mettre en place une police, une politique et une économie du langage. L'auteur insiste sur la politique du langage valorisée par Diderot. Celui-ci condamne la censure dans la mesure où elle invite au déguisement de la pensée et produit ainsi le trouble et la confusion, où elle fait de la publicité à ce qu'elle interdit. À la police des lettres, il faut substituer une politique des lettres qui permettrait la critique et servirait le pouvoir. 
Le dernier article de la première partie du recueil est consacré aux conseils et à l'éloquence philosophique dans la théorie de l'action politique chez Kant. Après avoir rappelé et démontré que « l'action pratique n'est pas le déploiement d'un acte intellectuel de connaissance » (p. 132), Robert Damien pose la question de la possibilité même de l'action dans un cadre où il n'y a ni théologie de l'autorité, ni autorité naturelle. Quel peut être alors le rôle politique du philosophe s'il n'y a plus de savoir de l'autorité ? À cette question, l'auteur répond que Kant ne renonce pas à l'idée d'une action philosophique de conseil, laquelle prend la forme d'une géopolitique de la réflexion politique (le philosophe incarne l'autorité sans pouvoir d'un Idéal, médium entre les espérances du peuple et les exigences de la souveraineté, il «agit sur la volonté du politique d'être le sujet moral d'une action politique », p. 143), d'une esth/éthique de l'autorité (le respect que j'éprouve pour autrui me permettant de considérer en quoi je manque à moi-même ainsi que de définir mon devenir), ainsi que d'une excentricité centrale de la statistique (le philosophe favoriserait l'accomplissement éthique de l'humanité en produisant une science de l'histoire de la liberté humaine qui aurait valeur d'idéal régulateur).

Jean Robelin ouvre la seconde partie du recueil par une réflexion sur les métaphores politiques chez le cardinal de Bérulle. L'auteur commence par souligner l'usage paradoxal que Bérulle fait de la métaphore : «Plus Bérule [sic] s'efforce de réduire l'écart métaphorique entre les symboles que la métaphore véhicule et le symbolisé, plus il transporte dans la religion une conception politique et plus son discours devient ainsi métaphorique » (p. 167). Ainsi, le pouvoir de Dieu est son essence même car l'œuvre appartient à son créateur. Le droit naturel se déduit de la hiérarchie de l'être. Mais la translation de sens instituée par le système métaphorique ne se fait pas à sens unique dans la mesure où elle produit aussi l'idée d'une certaine politique juste, à savoir la politique chrétienne. La négation de l'autonomie du politique s'appuie donc sur une conception de la religion en termes politiques. La fin de l'article est consacré à la démonstration du caractère impolitique du pouvoir divin fondateur du pouvoir politique. Le pouvoir divin est au-delà du pouvoir en ce qu'il ne commande rien, mais donne; or ce don appelle l'abandon du pouvoir humain en même temps qu'il fonde ce dernier.

L'article de Sophie Gouverneur nous livre une analyse des Provinciales de Pascal centrée sur la double tension entre « la dénonciation pascalienne des tromperies de la casuistique et sa légitimation de la tromperie d'une part dans sa propre pratique du langage, d'autre part dans sa théorie politique » (p. 186). Après avoir montré précisément en quoi la casuistique (doctrine de la « restriction mentale», doctrine des « équivoques », doctrine de la «direction d'intention ») est une subversion du langage condamnable d'un point de vue moral, politique et théologique, l'auteur insiste sur le fait que Pascal use du même argument que les Jésuites, à savoir celui de l'innocence théologique, pour légitimer certaines de ses pratiques comme l'anonymat et le double-jeu. Comment comprendre ce qui apparaît comme une incohérence? Tout d'abord, il faut remarquer que l'équivocité est la modalité de la parole divine; par ailleurs, c'est la nature même du politique et la nécessité de l'obéissance qui justifient l'usage de la tromperie. Ces arguments n'annulent certes pas la tension selon l'auteur, mais participent à son éclaircissement.

Delphine Antoine propose une analyse détaillée de la conception du langage de Géraud de Cordemoy. Après avoir montré que ce dernier établit une différence de 
nature entre la motricité et la volonté « tout en défendant l'existence d'un rapport nécessaire et indubitable, tout le temps de cette vie, entre ces deux puissances constitutives de l'être humain » (p. 219), l'auteur étudie le mécanisme de la causalité occasionnelle à travers l'exemple paradigmatique du langage. Ainsi, pour Cordemoy, la volonté est impuissante devant les mouvements corporels en rapport avec la conservation de la vie; cependant, l'absence d'un pouvoir producteur n'implique pas nécessairement l'absence d'un pouvoir directeur de l'âme. C'est pourquoi, l'institution par l'homme d'une convention entre des signes et des idées est possible et fondée dans l'institution par Dieu d'un rapport entre mon corps et mon âme. L'auteur termine son article en soulevant le problème d'un pouvoir sur le langage: selon Cordemoy, l'éloquence n'est jamais aussi puissante que lorsqu'elle est au service de la vérité, laquelle suppose la connaissance de Dieu, et non sa vision, ce en quoi il se sépare de Malebranche.

C'est à cet auteur qu'est consacré le dernier article du recueil. Jean Robelin commence par souligner le fait que même si la vérité se définit comme vision et évidence, une rhétorique de l'ordre est cependant bien présente chez Malebranche. Cette rhétorique de l'ordre prend la forme de la prédication. À travers elle, c'est la vérité elle-même qui parle à la raison et aux sens, c'est la Sagesse qui investit « la puissance diabolique» (p. 251) qu'est le langage tout en inversant les signes. L'auteur s'attache ensuite à montrer que c'est parce que Dieu constitue ontologiquement toute puissance qu'elle est légitime et qu'elle ordonne la société civile à une fin surnaturelle. Cependant, le péché originel explique que la raison se dise dans la force. Le prince est plus proche de Dieu comme puissance que de Dieu comme raison. Cela signifie-t-il pour autant que l'on doive une obéissance absolue au prince? La réponse est négative car l'ordre est une limite morale au pouvoir politique, il est «l'impolitique de la politique » (p. 262), lequel se manifeste dans la paix.

Cécile Nicco

Gérard Labrot, Sisyphes chrétiens. La longue patience des évêques bâtisseurs du royaume de Naples (1590-1760). Seyssel, Champ Vallon, 1999. 15,5 × 24, 256 p. (Époques).

L'histoire de l'architecture, entendue comme l'histoire de la construction des bâtiments, n'a pas pour habitude de définir ses espaces d'intervention. Les études sont envisagées selon l'angle chronologique de l'adjonction des pierres et de leurs formes, elles traquent les architectes et les commanditaires dans leurs déplacements, elles confrontent les résultats aux modèles courants et constatent d'éventuelles évolutions. Il n'est pas fréquent de voir les auteurs replacer leurs observations dans un contexte plus général qui permettrait d'appréhender l'étendue des réflexions menées, et de tester le niveau de généralisation ou de particularisme rencontré.

L'ouvrage de Gérard Labrot propose la démarche inverse : il s'éloigne le plus possible du regard qui, en individualisant les réalisations, ne conduit qu'à une juxtaposition de constats et préfère envisager le problème de l'architecture épiscopale 
sous l'angle de son territoire d'application. On ne lit donc pas cet ouvrage pour y apprendre une quelconque nouveauté intrinsèque à l'histoire d'un édifice en particulier mais plutôt pour comprendre, occasion rare, les limites et les contraintes du terrain sur lequel les réalisations prennent place. Les amateurs de données brutes y puiseront cependant quantité d'informations souvent inconnues sur les évêchés les plus célèbres comme les plus isolés; mais l'absence d'un index locorum les obligera à suivre l'ensemble de la démarche historique ici proposée.

Si l'auteur perd volontairement son lecteur dans le dédale des faits, c'est pour mieux saisir l'étendue du domaine d'action des évêques bâtisseurs sous ses différents aspects : géographique et historique certes mais surtout économique, relationnel, dogmatique et symbolique. Le champ d'application de l'étude est clairement défini : il s'agit de la conception que les évêques du royaume de Naples possèdent de leur propre patrimoine immobilier et des remèdes employés pour le faire évoluer. Il ne s'agit pas exactement ici d'architecture, au sens strict du terme répondant aux critères néovitruviens, il ne s'agit pas non plus seulement de bâtiment, son équivalent vulgaire dénué de tout style sinon d'une empreinte dite vernaculaire. Dans Sisyphes chrétiens, c'est l'ensemble de la construction qui est en jeu, au sens de l'édification de l'évêché, nouant indissociablement ses composantes matérielles et immatérielles. L'auteur montre combien il serait illusoire de vouloir envisager l'action apostolique et politique des évêques sans aborder le problème des lieux bâtis qui sont bien plus que de simples enveloppes. Parallèlement, il souligne que l'étude des éléments les plus élevés de l'architecture, cathédrales et palais épiscopaux à propos desquels leurs commanditaires ne tarissent pas d'éloges, trouve un nouveau sens à la lumière de la vision que les évêques ont de leur patrimoine et à la connaissance de la fonction qu'ils leur assignent dans un programme général. C'est ainsi l'ensemble de l'histoire de l'architecture qui se trouve enrichie par cette approche minutieuse et patiente.

L'objet d'étude est construit autour du document exploité. La tradition des visites ad limina, instituée par Sixte-Quint, s'exprime à travers des rapports périodiquement envoyés à Rome par les évêques contenant une description de l'état matériel et moral de leur juridiction. Dans un ouvrage précédent (Quand l'histoire murmure, Rome, École française de Rome, 1995), Labrot s'était déjà livré à l'exercice fastidieux mais productif de l'exploitation exclusive mais exhaustive d'une seule série documentaire. Il s'agissait alors, à travers l'étude des apprezzi, estimations d'un fief réalisées par des techniciens afin d'en apprécier la valeur marchande à l'occasion d'une transaction, de comprendre la part des composantes matérielles (habitat rural et urbain, casali, places, églises, etc.) dans les constructions historiques. L'auteur était alors parvenu à d'édifiantes réflexions notamment sur les rapports spatiotemporels entre la forme et la fonction d'un type de bâtiment.

La question qui le préoccupe aujourd'hui est géographiquement plus restreinte, car elle ne concerne qu'une portion de la terre, étudiée à travers le discours de l'un de ses acteurs les plus puissants. L'ouvrage situe les auteurs de ces documents et souligne l'importance numérique des Espagnols parmi les évêques tout en signalant le désintérêt de ces derniers pour le patrimoine bâti, si on les compare à ceux descendant de la noblesse locale. Les aristocrates napolitains sont les plus actifs, ils disposent en effet d'un réseau local non négligeable mais leur engagement est aussi lié à l'aspiration de rendre leur possession symbolique de ces contrées toujours plus 
visible. De nombreux facteurs cependant jouent un rôle dans le dynamisme dont certains font part. Leur capacité à gérer le patrimoine collectif, la mensa, l'intérêt porté par les feudataires et les associations de citoyens ou les confréries, déterminent pour partie le rythme et l'ampleur des chantiers engagés. Le plus souvent, les prélats présentent leur action devant Rome comme parsemée de multiples obstacles: les malheurs des invasions ottomanes et des catastrophes naturelles, un clergé séculier inculte et indifférent, des revenus en continuelle perte de vitesse... Lorsqu'ils sont aptes à réagir, ils tentent alors de relancer l'activité économique mais installent aussi des communautés de réguliers, issus des nouveaux ordres ou des ordres mendiants. Pour peu qu'ils aient la chance de résider dans des centres attractifs, ils recrutent des enseignants de qualité pour les séminaires. Enfin, ils stimulent la motivation du peuple en renouvelant le culte des saints locaux et en valorisant les reliques possédées. Mais il apparait très nettement qu'il n'existe aucune règle généralisable. Certaines communautés très isolées peuvent montrer une richesse relative alors qu'on ne sait trop pourquoi, mais des cités dynamiques possèdent parfois des bâtiments dans un état déplorable et il faut attendre longtemps les perspectives d'amélioration. Ainsi, l'étude verticale de l'un ou l'autre des évêchés n'aurait pu présenter que des conclusions atypiques et la présentation transversale de ces documents prend tout son sens. Les deux critères qui guident les œuvres des évêques sont la qualité et la conformité. Qualité des conditions d'exercice de leur séminaire avant tout, mais qualité de vie également. Lorsqu'ils possèdent des fortunes personnelles, ils les consacrent volontiers aux palais épiscopaux et à leurs jardins mais aussi parfois aux chapelles tutélaires. Conformité des bâtiments de culte aux articles du concile tridentin et aux recommandations contemporaines en matière de fabrique ecclésiastique, comme celles formulées par Charles Borromée ou Tobia Corona. Lorsqu'ils ne reconstruisent pas, ils réaménagent l'espace liturgique pour respecter les consignes de séparation entre les fidèles et le clergé. On retiendra les mots écrits en 1702 par l'évêque de Conversano qui a voulu « donner au chœur l'apparence d'un théâtre parfaitement adapté à la célébration des rites et des cérémonies ». Peu d'entre eux sont véritablement sensibles à transformer le palais en une « habitation de formes modernes » (Salerne, 1637), à orner la cathédrale d'un plafond "comme l'exige l'art le plus élégant de notre siècle » (Nole, près de Naples, 1652), à remplacer le maître-autel par « un nouveau sur le modèle romain, de forme élégante, en marbre sculpté » (Vieste, 1699). Les améliorations matérielles ne signifient pas toujours embellissements et l'esthétique qui a présidé à leurs choix est plus souvent subie que véritablement élaborée.

La présentation de ce panorama tend à montrer que les évolutions ont lieu sur la longue durée, que si l'apparence des évêchés se trouve profondément modifiée en l'espace d'un siècle et demi, cela se produit presque à l'insu de la volonté des acteurs qui préfèrent généralement se placer dans une continuité causa sui et somme toute apathique. Et contre toute attente, ce cours de l'histoire maintient son cap en dépit des perpétuelles ruptures et des changements permanents de personnels auxquels les évêchés sont soumis. Le destin individuel de chacun de ces évêques bâtisseurs disparaît alors dans un projet collectif qui les dépasse et vise principalement au maintien en place de l'Église sur l'ensemble du territoire.

Pascal Dubourg Glatigny 
Charlotte de CAstelnau-L'Estolle, Les Ouvriers d'une vigne stérile. Les Jésuites et la conversion des Indiens au Brésil, 1580-1620. Lisbonne/Paris, Fundação Calouste Gulbenkian/Centre culturel Calouste Gulbenkian, 2000. $18 \times 25$, 559 p., sources, tabl., bibliogr., cartes, ill. (Commission nationale pour les commémorations des découvertes portugaises).

La métaphore qui sert d'intitulé à ce livre est du général de l'Ordre, Claudio Aquaviva (1581-1615), et elle sert de fil conducteur à un travail abondamment documenté, très bien composé, luxueusement édité par le Centre culturel Calouste Gulbenkian.

Le dessein de l'auteur surprendra ceux qui s'attendraient à trouver ici un complément à l'Histoire de la compagnie de Jésus au Brésil, déjà contée de 1938 à 1950 par le P. Serafim Leite, ou à l'Histoire des Indiens du Brésil de Manuela Carneiro da Cunha (1992). Il s'agit « de comprendre ce qui fonde la démarche des missionnaires jésuites du Brésil au XVI e siècle », de «tenter de faire apparaître les "catégories" de pensée des jésuites, de restituer le sens qu'ils donnaient à leur démarche » (p. 21). Charlotte de Castelnau-L'Estoile le répète au terme de son parcours (p. 501) : elle a voulu utiliser « les propres catégories d'analyse et de perception des missionnaires », sans « recourir à des jugements de valeur portés a posteriori $»$. Une gageure, sans doute, mais pari tenu.

Dans la très abondante documentation dont le livre est tiré, beaucoup de textes étaient connus, mais ils avaient été édités à d'autres fins, lus d'un autre point de vue. Ils sont repris ici dans une perspective nouvelle, et dans le cadre strict que s'est imposé l'auteur. Ils y prennent un autre sens, en eux-mêmes et les uns par rapport aux autres, comme les pièces colorées d'un kaléidoscope, lorsque l'appareil tourne sur son axe. Et comme il arrive fréquemment quand on revisite les archives connues, des documents inédits ou méconnus viennent au jour, auxquels nul n'avait encore vraiment prêté attention. Il y a beaucoup de ces « retrouvailles » heureuses dans le livre, comme le récit par Corrado Arizzi des fêtes en l'honneur de la canonisation d'Ignace de Loyola et de François Xavier, célébrée en décembre 1622 à Salvador de Bahia, qui est repris et expliqué dans l'épilogue (p. 479-491).

L'ensemble s'ordonne autour d'une question centrale, celle des aldeias, une création brésilienne originale désignant deux types d'implantation jésuite: villages regroupant des Indiens sous l'autorité de missionnaires qui les évangélisent et les civilisent en même temps, ou villages indiens de création non jésuite où les pères se rendent parfois de façon temporaire (p. 48). Dans la période considérée, ces aldeias sont un sujet constant de frictions et de polémiques entre la tête de la Compagnie, qui est à Rome, le provincial du Brésil, le pouvoir royal, dont le siège est alors à Madrid, le gouverneur qui le représente sur place, et les colons, dont les intérêts s'opposent le plus souvent à ceux des pères; un contexte changeant et complexe dans lequel il s'agit certes d'évangéliser et de civiliser les Indiens, mais aussi et surtout de sauvegarder l'identité jésuite, de maintenir la cohésion de la Compagnie, fût-ce au prix de l'échec de sa mission. De là vient que la masse des archives consultées, et la rumeur innombrable des voix jésuites qui s'y entrecroisent et s'y répondent, semblent s'engouffrer au final dans un véritable trou noir, celui du «silence des Indiens » sur lequel se construisit là-bas l'entreprise missionnaire (p. 499). 
Onze chapitres ponctuent cet itinéraire inexorable, tous construits eux-mêmes autour d'un texte ou d'un ensemble cohérent de textes apparentés.

Le premier est axé sur le récit de voyage rédigé par le jeune jésuite qui avait accompagné le visiteur Cristóvão de Gouveia au Brésil en 1583, Fernão Cardim. C'est le «tableau idyllique d'une nouvelle humanité régénérée par son évangélisation ». Idyllique, mais fragile, si l'on songe que les mêmes Indiens, qui chantent «des cantiques pieux sous la conduite des pères », sont capables aussi, le temps d'une fête, de se muer en guerriers imitant les bêtes sauvages, et d'y exalter les exploits sanguinaires de leurs ancêtres.

Le deuxième et le troisième chapitres sont consacrés au rapport fait à Rome par le visiteur lui-même, dans le cadre rigoureusement réglé des échanges que la bureaucratie de l'Ordre impose à ses membres, à tous les niveaux de sa hiérarchie. C'est un bilan critique des trente premières années de la mission, dans lequel l'aldeia, dont le statut civil est des plus flous, est présentée comme le lieu idéal où les pères, comme les Indiens, peuvent le mieux assurer leur salut. Ce à quoi s'opposent les Indiens, jaloux de leur liberté, les colons que les Indiens n'intéressent que pour leur force de travail, et Rome, qui voit de loin les dangers que la cohabitation imposée aux religieux leur fait courir. Le règlement élaboré par Gouveia en 1586 a pour but de dénouer toutes ces contradictions, pour le plus grand bien des Indiens et des pères, sans déplaire aux colons ni trop déplaire à Rome.

Le centre de gravité du problème, qui ressemble à celui de la quadrature du cercle, se déplace au quatrième chapitre, à propos de l'apprentissage de la langue des Indiens, et notamment du tupi. Les Constitutions de la Compagnie recommandaient l'apprentissage des langues indigènes, sans plus. Et jusqu'à la visite de Gouveia la pratique des jésuites était restée empirique : peu de pères savaient le tupi, et ceux qui arrivaient du Portugal répugnaient d'autant plus à l'apprendre que ce n'était pas une langue écrite. Gouveia plaida donc à Rome pour que l'apprentissage se fît dans les aldeias, au contact direct des Indiens.

Mais qui étaient les missionnaires envoyés au Brésil, ou recrutés plus rarement sur place parmi les créoles? Les chapitres v et vi en donnent une typologie extrêmement précise, sur la base de deux catalogues qui se recoupent et se complètent. On est surpris d'y apprendre qu'en 1598 la Compagnie ne comptait que 164 membres au Brésil, dont la moitié à peu près étaient des pères, généralement d'un faible niveau intellectuel, et dont 23 seulement vivaient dans une aldeia. Soixante-dix d'entre eux, dans les aldeias, les collèges et les résidences, avaient une connaissance plus ou moins approfondie du tupi. Paradoxalement, ceux qui réussissaient le mieux dans le travail de l'évangélisation étaient ceux qui avaient le moins de connaissances générales, mais savaient parler et entendre le tupi. C'étaient le plus souvent des coadjuteurs spirituels, c'est-à-dire des prêtres qui n'avaient pas prononcé et ne prononceraient jamais le quatrième vœu, qui seul «fait» le jésuite. Chaque aldeia était sous la responsabilité d'un père et d'un frère, alors qu'à la fin du siècle Rome eût préféré que ce nombre fût doublé, pour renforcer la discipline. On tenta de le doubler en effet, mais sans succès : les pères contraints d'aller dans les aldeias sombraient dans la mélancolie, cédaient aux appas que leur tendaient innocemment les Indiennes, ou se livraient sur les indigènes à des actes de violence. Les représentants des colons ne manquèrent pas de faire savoir à Madrid ce qu'ils pensaient d'une conduite aussi scandaleuse. Rome sanctionna, mais avec prudence : il y avait trop 
peu de missionnaires sur le terrain, et ils étaient trop fragilisés pour qu'on pût sévir avec rigueur.

Les représentations des colons ressortissaient d'ailleurs plus à la jalousie qu'à une éthique dont ils ne s'embarrassaient guère eux-mêmes. Le chapitre viI montre que les jésuites et eux étaient rivaux dans le domaine de la production et du commerce du sucre, et par conséquent dans l'utilisation et le traitement de la main-d'œuvre indigène; ce qui posait naturellement la question du pouvoir des jésuites dans les aldeias. Les missionnaires prétendaient être des médiateurs incontournables entre le pouvoir royal et les Indiens, et deux lois de 1595 et 1596 leur reconnurent en effet ce rôle. Mais le général de l'Ordre était d'un avis tout autre. En 1597, il fit savoir au provincial que les jésuites ne devaient s'occuper que des affaires spirituelles des Indiens. Rodrigues lui opposa que sans autorité sur les Indiens les pères ne seraient plus crédibles à leurs yeux. Rome dut temporiser, une fois encore.

À la fin du généralat d'Aquaviva (chapitre vIII), toute la Compagnie s'interrogea sur son identité et sur son projet. Aquaviva avait écrit dès 1581 une lettre à tous les jésuites leur enjoignant de retrouver le véritable esprit missionnaire qui avait présidé à la fondation de l'Ordre. Au Brésil, par exemple, il eut fallu qu'il y eût dans les aldeias «conformité dans le Spirituel comme dans les collèges ». Mais cela se révéla impossible. Le P. Jácome Monteiro, qui accompagna le visiteur Manuel de Lima au Brésil en 1607, écrivit à Aquaviva, à son retour, qu'à son avis le plus expédient serait d'abandonner les aldeias à la première occasion (p. 311). Mais la province brésilienne défendit sa singularité et en demanda même le renforcement : que les aldeias se repeuplent, qu'elles soient mieux adaptées aux coutumes indiennes, que les missionnaires qui y résident soient requis de mieux connaître la langue des Indiens. Ce point de vue l'emporta finalement au prix de quelques accommodements avec Madrid et avec Rome.

À côté de l'abondante documentation à laquelle ont été puisés les huit premiers chapitres du livre, les trois derniers sont consacrés à la littérature missionnaire proprement dite : écrits de consolation, curiosa, relations d'expéditions, hagiographie. L'intérêt de la lecture qui en est faite est de les mettre en situation dans le contexte précédemment décrit, relativement à la position qu'occupent les scripteurs dans la hiérarchie de l'Ordre, à la qualité des destinataires visés, et à la finalité d'une stratégie qui n'est perdue de vue ni par les uns ni par les autres, qu'il s'agisse de la relation de Fernão Cardim, déjà citée, de la Relation du Brésil de Jácome Monteiro (1610), de la Relation de la mission du Maranhão de Luís Figueira (1609), ou des versions successives de la vie édifiante du P. José de Anchieta, depuis celle de Quirício Caxa (1598) jusqu'à celle de Pero Rodrigues, devenu finalement l'hagiographe d'Anchieta, qu'il n'aimait pourtant guère de son vivant, « pour la plus grande gloire de la province jésuite brésilienne» (p. 476, n. 68).

Les missionnaires, dans leurs lettres, et l'auteur de ce livre à leur suite, fait souvent à leur désavantage la comparaison qui semble s'imposer entre les succès éclatants remportés par la Compagnie au Japon, au moins jusqu'au tournant du XvI ${ }^{\mathrm{e}}$ $\mathrm{au} \mathrm{XVII}^{\mathrm{e}}$ siècle, et la minceur des résultats obtenus dans la vigne brésilienne. La faute en est généralement imputée au «terrain »: les Japonais, peuple de très ancienne culture, paraissant bien supérieurs aux sauvages que les Indiens étaient encore aux yeux des Portugais. 
On se refusera ici à discuter le bien-fondé de cette comparaison, au nom même des principes énoncés par Charlotte de Castelnau-L'Estoile : il faut en effet s'interdire les «jugements de valeur portés a posteriori $»$. On peut seulement regretter que la méthode suivie, si féconde à bien des égards, et le type de documentation retenu empêchent de poser à propos du Brésil des questions que l'expérience japonaise pose à la même époque. En voici deux : comment les jésuites américains faisaientils passer la doutrina en tupi, à partir des formulations qui s'imposaient traditionnellement à eux en latin ou en portugais? Et parmi tant de jésuites qui furent exclus de la mission, ou qui quittèrent d'eux-mêmes la Compagnie, n'y en eut-il aucun pour s'interroger, non pas tant sur la discipline qui lui était imposée ou sur son vœu de chasteté, que sur les fondements même de sa croyance, comme le fit le P. Crístóvão Ferreira au Japon, après avoir apostasié?

Jacques Proust

Jean-Louis Quantin, Le Catholicisme classique et les Pères de l'Église. Un retour aux sources (1669-1713). Paris, Institut d'études augustiniennes/Turnhout/Diff. Brepols Publishers, 1999. $16 \times 24,680$ p., bibliogr., index (Collection des Études augustiniennes, sér. Moyen Âge et Temps modernes, 33).

Si l'auteur avait tant soit peu sacrifié au style journalistique qu'affectionnent les jeunes historiens de sa génération, il aurait pu intituler son étude : «Les Pères, le pape, les évêques et les dragons ». Mais il n'a cure de ces facilités d'écriture et, à un sujet sérieux, il affecte un titre sans clin d'œil, de même qu'il poursuit ses démonstrations historiques dans un français élégant et clair, souligné parfois d'une expression au parfum de jadis, comme « trancher du critique » (p. 299) qu'il n'a pas dû lire dans notre presse parlée ou écrite. Mais ce n'est pas seulement par l'écriture que Jean-Louis Quantin se met à la hauteur de son grand et complexe sujet. Il y apporte les ressources d'une très vaste érudition, toujours contrôlée et énergiquement distribuée. Il a fréquenté en effet non seulement les maitres français de la pensée religieuse du XVII ${ }^{\mathrm{e}}$ siècle (Jacques Le Brun, Bruno Neveu, Philippe Sellier), mais aussi les historiens anglais, au cours d'un séjour prolongé à Oxford.

La première partie de l'œuvre invite le lecteur à apprendre, avant toutes choses, ce qu'est un Père de l'Église. La définition est plus ou moins extensive et couvre souvent tous les auteurs ecclésiastiques jusqu'à l'avènement de la scolastique au $\mathrm{XII}^{\mathrm{e}}$ siècle (Bernard de Clairvaux inclus). Comment ensuite établir l'autorité de ces écrivains, dont le concile de Trente, en sa quatrième session, a déclaré que le consensus (s'il porte sur une matière de foi ou de mœurs) constitue une interprétation contraignante des textes de l'Écriture sainte? La séparation entre écrits authentiques et supposés constitue évidemment une opération préalable, dont les controversistes de la fin du XVI ${ }^{\mathrm{e}}$ siècle n'ont pas eu suffisamment la préoccupation et qui va enchanter l'érudition gallicane, soucieuse jusqu'à l'obsession de fixer les traits de la véritable Antiquité, puisque Antiquité est synonyme de vérité dans la doctrine et de pureté dans les mœurs. Avec pénétration, et à plusieurs reprises, 
l'auteur insiste sur l'importance décisive de ce souci érudit, dans la longue durée de l'histoire de l'Église catholique. La vérité n'est plus dite par le pape ou les évêques mais par l'historien : les questions de droit sont tranchées par l'établissement des faits. C'est ce que les jansénistes, qui expriment de la façon la plus cassante les maximes de l'érudition gallicane, ne cessent d'opposer à la hiérarchie de l'Église, qui prétend à tort (selon eux) mieux connaître qu'eux la véritable pensée de saint Augustin (parce que, rappelons-le, ils affirment que la doctrine de Jansénius ne représente rien d'autre que la pure doctrine de l'évêque d'Hippone).

La seconde partie de l'œuvre décrit les différents emplois des Pères par le catholicisme classique. Leurs écrits constituent l'arsenal des controversistes contre les « innovations » de la foi protestante. Et si la subtile clairvoyance du ministre Jean Daillé met en évidence la difficulté de montrer, sur un point quelconque de la doctrine romaine, le fameux « consensus » des Pères, la polémique de Port-Royal coupera court aux difficultés de la «voie d'examen » en proposant un argument de prescription: vu l'importance de la doctrine eucharistique, si l'Église du $x^{\mathrm{e}}$ siècle avait inventé la présence réelle, comment ce changement n'eut-il pas provoqué des récriminations et des protestations dont l'histoire ne nous offre aucun indice? À usage interne, les Pères se prêtent à de multiples emplois : stimuler la piété par l'exemple des «Saints Pères », hérö̈ques témoins de la foi en sa vigoureuse jeunesse; opérer le tri entre la solide et pure dévotion et les déviations de la religion populaire ou de la piété jésuite (comme les exagérations de la dévotion mariale et la pratique envahissante de l'exposition du Saint-Sacrement); offrir les usages de l'Église antique comme remèdes aux affadissements ou aux occultations du présent (lecture de l'Écriture par les fidèles, retour à la pénitence publique, participation des laïcs à la messe).

Ce bref et schématique résumé dissimule à regret la richesse, toujours renouvelée, des analyses de Quantin, dont l'intérêt ne faiblit pas au cours des 590 pages du texte (le reste étant rempli par la bibliographie et les index). Cette ouvre riche est aussi une œuvre marquante, destinée à durer, par sa rigueur historique, par son intelligence impartiale des logiques en présence, par la longue portée de ses conclusions. Dès son introduction, l'auteur affirme vouloir écrire en historien, et rien qu'en historien (donc sans se prononcer sur la teneur des affirmations dogmatiques qu'il rencontre). Ce propos commande l'architecture de l'œuvre, qui n'ajoute pas un chapitre à l'histoire de la théologie (à la différence, par exemple, d'un livre comme celui de George Tavard, La Tradition au XviI ${ }^{e}$ siècle en France et en Angleterre, Paris, Cerf, 1969). L'étude des Pères, leurs éditions, leurs traductions sont constamment situées dans une stratégie à multiples orientations : employer la science historique à l'établissement de la «perpétuité de la foi » et à la justification du «primitivisme » gallican (retour à l'Église antique), ce qui vaut à la fois pour réfutation de « l'hérésie » et pour condamnation un peu hautaine, ensemble cléricale et docte, des facilités de la religion populaire et des accommodations jésuites. L'attachement aux Pères rassemble en les liant fortement les convictions du catholicisme français du XviI ${ }^{\mathrm{e}}$ siècle : l'adéquation de la vérité et de l'Antiquité, moyen court de rejeter l'innovation du huguenot ou du casuiste, la rigueur spirituelle, effet en retour du déchirement de la Réforme, l'aspiration passionnée à l'unité religieuse du royaume, héritage de l'histoire. 
L'impartialité de l'auteur se remarque en ce qu'il note les forces et les faiblesses de chacun : il admire la rigueur argumentative du protestant Daillé, qui n'a pas de successeurs de sa valeur dans les vingt années qui précèdent la Révocation. Il ne cache pas le recours constant et unanime des controversistes catholiques aux fulminations d'Augustin contre les donatistes : l'usage des Pères justifie la politique religieuse du grand roi et de ses conseillers, à savoir l'emploi de la contrainte en matière de religion, ce que même les jansénistes ne refusèrent pas d'admettre (quand elle n'était pas employée contre eux). Et bien que l'effort soutenu, exigé de l'enquêteur par ce grand travail érudit, ne puisse aller sans quelque admiration pour ses devanciers du Grand Siècle, Quantin avertit loyalement de leurs aveuglements et de leurs faiblesses, ce qui nous invite à visiter ses conclusions.

Se plaçant d'abord à l'extérieur de l'Église gallicane, l'auteur affirme que l'autorité accordée à l'histoire et à l'établissement des faits agit à long terme comme une dissolution de l'orthodoxie, puisque les faits sont invoqués contre les décisions doctrinales de l'Église. Les protestants, avec Bayle, ne se sont pas privés d'insister sur cette contradiction interne du catholicisme. Vue de l'intérieur, la situation n'est pas meilleure. L'acharnement des gallicans à privilégier les premiers siècles chrétiens comportait au moins deux inconvénients : celui de couper le peuple chrétien et les pauvres gens du ressourcement qu'ils trouvaient dans les cérémonies et dévotions traditionnelles; celui de s'opposer à toute évolution des croyances et des pratiques, en instituant le passé comme juge du présent, sans faciliter pour autant le débat sur l'époque paléochrétienne avec les protestants, qui découpaient ce passé autrement (les anglicans s'intéressaient avant tout aux Pères anténicéens, tandis que pour les gallicans l'âge normatif de la patristique se plaçait au $\mathrm{IV}^{\mathrm{e}}$ siècle).

En terminant, Quantin recherche l'explication souterraine de la passion gallicane pour l'étude et l'usage des Pères. Il la voit d'abord comme l'élément fédérateur d'un milieu universitaire frustré de sa puissance sociale par un réseau politico-religieux où se rencontrent des grands à la vie peu édifiante et des personnages d'Église sans profonde culture théologique. Il la décrit ensuite comme une nostalgie de la pureté, connotée d'un fort refus de la chair et de ses sollicitations indiscrètes. Et les dernières lignes du livre ne seraient pas désavouées par Jean Delumeau : «Le catholicisme classique est [...] un christianisme, au total, dans lequel le vendredi saint est souvent plus apparent que le dimanche de Pâques » (p. 591). Quoi qu'il en soit de ces interprétations, ce livre éclaire remarquablement la théologie «néogallicane » : primitiviste et antiromaine, elle se durcira au $\mathrm{XVIII}^{\mathrm{e}}$ siècle dans la résistance à la constitution Unigenitus et forme l'horizon de la politique religieuse de la Constituante.

L'exhaustivité de l'enquête menée par Quantin, la clarté et la fermeté de ses démonstrations invitent le recenseur de son livre à entrer en débat avec lui. Avant cela, on pourra exprimer le regret que les positions de Richard Simon n'aient été évoquées qu'en quelques lignes (p. 105). Il semble que Simon méritait un peu mieux : il est intervenu dans la querelle ouverte par la Perpétuité de la foi en contestant la documentation de ses ennemis les jansénistes; il s'est efforcé de restreindre la portée du consensus des Pères aux strictes limites décrétées à Trente et d'exclure du consensus dogmatique la doctrine de saint Augustin sur la grâce; enfin, sa fixation obstinée à la détermination du sens littéral l'amène à une appréciation critique 
de l'exégèse patristique. Chez lui aussi, la relation à l'héritage reçu des Pères s'effectue dans le climat polémique auquel l'auteur nous a rendus sensibles.

Le souci affirmé et répété de rigueur historique amène Quantin à donner, dans ses notes, de petits coups de règle sur les doigts des théologiens, catéchètes et liturgistes qui se sont mêlés d'histoire (André Dhôtel, Pierre Jounel, Louis Bouyer, et je dois en oublier). Il faudrait considérer, avec plus de compréhension, que le lieu d'où ils écrivent est généralement celui d'experts, en charge d'éclairer les hommes de gouvernement : dans cette perspective, leur étude historique s'accompagne nécessairement d'une évaluation des pratiques passées, légitime en son lieu et en son ordre, puisqu'elle ne se propose au fond que de montrer les «variations » de l'Église catholique. Dans un registre voisin, on se demandera si le processus de détachement produit par une pastorale désacralisante est seulement dû à l'effet pervers entraîné par l'obstination des «dénicheurs de saints »: l'affaire est plus complexe, comme en témoigne l'importante conclusion de la thèse de Marc Venard sur le diocèse d'Avignon (voir Revue de synthèse, 4e sér., 4, oct.-déc. 1995, p. 621-622).

Le point le plus profond et le plus sensible abordé par l'œuvre de Quantin est celui de la Tradition et de son statut dans le catholicisme posttridentin. Lui-même note le flou de la doctrine tridentine de la Tradition, sans évoquer sa cause principale : la tension non résolue entre l'autorité des conciles et celle du pape et le conflit non apaisé sur le «droit divin» des évêques. Surtout, comme il constate que le consensus des Pères est « le ventre mou » du catholicisme et ne peut être établi que par un immense effort érudit, il en conclut que l'autorité en matière doctrinale transite de la hiérarchie catholique aux historiens, ce qui fissure l'Église et mène, selon lui, au « suicide de l'orthodoxie ». Mais peut-on opposer totalement dans la France classique le camp des savants et celui des évêques? Il est certain que l'Église catholique au XVIII ${ }^{\mathrm{e}}$ siècle se replie sur l'argument de prescription et met en veilleuse la critique, mais, au XIX ${ }^{\mathrm{e}}$ siècle, quand elle cherche à réconcilier l'histoire et la foi par le moyen de «la science catholique », ne recourt-elle pas à Bossuet — amputé de son gallicanisme? Si bien que l'opposition de l'histoire, productrice de «faits », à l'autorité doctrinale de l'Église vaudrait principalement pour le «second jansénisme »? Il n'en reste pas moins, et on peut accorder ce point sans réticence aucune à l'auteur qu'il demeure dans le catholicisme une forte et, sans doute, insoluble tension entre la Tradition comme héritage reçu (d'où l'autorité des savants) et le magistère vivant, comme voix autorisée de la Tradition. Dans cette perspective, le livre de Jean-Louis Quantin est à lire non seulement par les historiens mais par les théologiens, qui «planchent » plus que jamais sur le sujet (voir les articles de J.-F. Chiron et B. Sesbouë, Recherches de science religieuse, oct.-déc. 1999 et janv.-mars 2000).

François LAPLANCHE

Alasdair MacIntyre, Après la vertu. Étude de théorie morale. Trad. de l'anglais par Laurent Bury. Paris, Presses universitaires de France, 1997. 17,4 × 24, 282 p., bibliogr., index (Léviathan).

Le lecteur français désirant découvrir les études anglo-saxonnes actuelles qui tentent de relire l'œuvre d'Aristote et de promouvoir sa pensée aujourd'hui, disposait déjà d'une 
traduction d'un ouvrage représentatif de MacIntyre : Quelle justice? Quelle rationalité ? Cependant, Après la vertu devait être traduit, car Quelle justice? Quelle rationalité? écrit plus tard n'en constitue en réalité que la suite.

L'auteur commence son livre par une «proposition dérangeante » (chap. I) qu'il voudra démontrer: d'après lui, le langage moral actuel se trouve dans un grand désordre, car, s'il continue à être utilisé, c'est par rapport à un contexte théorique et pratique lacunaire. Nous n'avons plus que des fragments du cadre conceptuel qui a autrefois donné sens au langage moral. Aussi sommes-nous pris dans des désaccords moraux et des débats interminables. En effet, les prémisses en opposition y sont inconciliables (par exemple, à propos de la justice sociale, l'exigence d'égalité et celle de liberté), et ce d'autant plus qu'elles puisent dans des traditions hétéroclites. Or cette affirmation est forcément paradoxale, c'est-à-dire imperceptible à la conscience commune qui ne soupçonne pas spontanément l'incohérence de son propre langage. Il faut donc une méthode qui puisse repérer ce lent processus d'occultation et d'oubli du contexte de la morale. L'auteur précise que la morale ne se réduit pas à des concepts, mais comprend des «pratiques, croyances et schémas conceptuels » (p. 1). Elle gagne à être approchée aussi par l'histoire et l'anthropologie. C'est donc une histoire de la philosophie que propose l'auteur, une histoire nonneutre, mais résolument évaluative qui s'inspire de Hegel et présente la philosophie comme un champ où les auteurs se réfutent, relèvent des défis, réussissent ou échouent. Le critère est celui de la « supériorité rationnelle» (p. 262) d'une théorie sur une autre, et on verra la théorie d'Aristote, pourtant antérieure, en être gratifiée, tandis que Kant ou Hume «échoueront », de façon peu hégélienne, face à Aristote.

Or, face à l'auteur se dresse l'émotivisme, selon lequel « tout jugement moral n'est rien d'autre que l'expression d'une préférence, d'une attitude ou d'un sentiment» (p. 14) et qui ramène tout choix moral à un choix subjectif. Il s'oppose doublement à lui : en tant qu'explication rivale qui, de son point de vue atemporel, ne peut voir de changement historique dans la morale ni reconnaître que la vision individualiste libérale de l'homme n'a pas toujours été la seule; en tant qu'objet d'étude ensuite, comme théorie dominante actuelle qui s'est développée dans le vide laissé par l'éviction progressive de l'aristotélisme.

Les deux principales traditions sont donc posées; il n'y a plus qu'à présenter cette histoire à rebours où la victoire de l'émotivisme sur le schéma aristotélicien est en réalité un échec de la morale.

Après avoir présenté l'imprégnation de l'émotivisme dans notre culture (chap. III à vIII), et l'alternative qui se présente à nous de choisir entre Aristote et Nietzsche (chap. Ix), l'auteur tente une reconstruction historique puis une réactualisation théorique de la morale aristotélicienne perdue dont le parti pris téléologique et collectif au sujet de la vertu est pourtant le seul qui puisse fonder une morale légitime (chap. $x$ à xv). La dégradation de cette tradition et ses perspectives actuelles sont présentées à la fin de l'ouvrage.

La signification de l'émotivisme ambiant est d'abord approfondie (chap. III). Il entraîne «l'oblitération de toute distinction réelle entre les relations manipulatives et non-manipulatives » (p. 25). Face à une morale qui n'est que l'expression de ma subjectivité, il ne peut exister en effet que des moyens pour mes désirs. Les fins et les valeurs ne se discutent plus, car elles sont juste données et traitées comme des 
faits; seuls les moyens seront discutés, ce qui est l'essence de la bureaucratie wébérienne. Une apparence de neutralité, qui n'est qu'un tabou sur les fins, rend possible la domination des uns par les autres. Dans le même mouvement se précise ce qui a pu être pris pour une émancipation : la désolidarisation (depuis Jean-Paul Sartre et Erving Goffmann) du soi vis-à-vis de tout rôle social qui pourrait l'aliéner, le masquer. Cette apesanteur sociale du « soi émotiviste » revendiquée est cependant loin de protéger l'individu, car elle rend inassignable et incommunicable le choix moral d'un individu dépourvu de critères et le dévalorise.

Ce complexe d'individualisme et de bureaucratie proviendrait de l'échec du projet de nos prédécesseurs des Lumières de fonder la morale de façon autonome (chap. Iv), projet pourtant rendu nécessaire par la dénonciation préalable de tout fondement hétéronome (théologique ou politique). Kierkegaard par le choix éthique, Kant par la raison, Hume par les passions, tous y auraient échoué. En effet, comment pouvait-il en être autrement, dès lors que, sous le coup de la critique antiscolastique et du rabaissement - janséniste autant que protestant - des prétentions de la raison à percevoir les fins humaines, on renonçait aussi à fonder l'autorité de la morale sur un quelconque « télos »? Une morale qui n'est justifiée que par les deux termes liés, d'une nature humaine donnée et de certaines règles à suivre, est incomplète : il faut lui joindre le troisième terme du bien humain, vers lequel les règles morales sont censées amener la nature humaine.

Or, ni les issues utilitaristes (chap. vI) cherchant dans le plaisir une nouvelle fin, ni les tentatives postkantiennes qui insistent sur le droit (comme celle d'Alan Gewirth) n'ont pu tirer la morale de cette impasse. L'utilité et les droits introuvables dans la philosophie conduisent à un troisième mythe lié à la sociologie : celui de l'efficacité, de la compétence directoriale à diriger les hommes. Le masque de neutralité sociologique y cache cette fois à peine l'instrumentalisation émotiviste de l'homme. Ce pseudo-savoir applique illégitimement la notion de fait à l'homme (qui inclut toujours aussi des valeurs) et omet l'irréductible imprévisibilité du comportement humain (chap. vII et VIII). Cet état des lieux dressé, le chapitre IX assure le rôle de charnière en posant l'alternative à laquelle accule cette extension de l'émotivisme : faut-il suivre Nietzsche qui démasque comme trompeuse toute prétention à l'objectivité morale, ou Aristote, et, comme lui, cesser de discuter isolément des seules règles, et oser chercher les fins à suivre dont découleront les règles ? L'auteur emprunte maintenant la seconde voie. Il commence par décrire chronologiquement ce qu'il reconstruira comme «tradition aristotélicienne », repérant ses racines dans la société homérique (chap. x) et la suivant jusqu'au Moyen Âge (chap. XIII), en passant par les sophistes, Platon, les tragédiens (chap. XI), et bien sûr Aristote (chap. XII). Une telle diversité s'unifie au moins par contraste avec nos conceptions actuelles en ce que l'homme, dans cette tradition, est toujours identifié socialement, son bien défini collectivement et les vertus considérées comme ce qui permet d'y parvenir. Contrairement à la morale de la loi pour la loi qu'inaugure le stoïcisme, Aristote insiste sur une morale des fins auxquelles est subordonnée la loi comme moyen de parvenir au bien. Le plaisir - en réponse anticipée aux utilitaristes - ne fait qu'accompagner la fin sans pouvoir suffisamment la définir. Le moment de la diversité maximale de cette tradition est relayé par les deux chapitres clés du livre (xIV et Xv) où MacIntyre conceptualise le matériau qu'il vient d'exposer pour 
jeter les bases d'un aristotélisme légitime et réactualisé. Son caractère distinctif est le suivant : les biens recherchés par la pratique vertueuse qui en est le moyen sont internes à cette pratique et ne peuvent s'obtenir sans elle (p. 180-181). L'utilitarisme au contraire ne voit la vertu que comme le moyen d'obtenir une fin qui lui est externe. Le développement conceptuel de la vertu suppose ensuite trois étapes solidaires. D'abord, qu'on la repère comme " pratique », au sens que l'auteur décide de donner à ce mot : une activité humaine coopérative et sociale, dont les biens internes sont obtenus en visant des normes reconnues, et qui étend les capacités humaines (p. 183). Mais les pratiques vertueuses doivent être ensuite coordonnées dans l'unité narrative d'une vie qui leur donne sens (chap. xv), la vie d'un individu responsable orientée vers la recherche du bien. L'intégration temporelle de la vertu est doublée d'une inclusion sociale de cette vie vertueuse dans le contexte d'une tradition qui lui donne sens, débat collectif et vivant sur la conception commune du bien.

Téléologie, unité d'une vie, présence de la communauté, tels sont les éléments manquant à l'intelligibilité du discours moral actuel, desquels MacIntyre achève de décrire la perte (chap. XvI) : les biens des pratiques sont souvent externes (le travail est aliéné notamment); l'unité de la vie est fragmentée en segments d'activités isolées; enfin, sauf dans cet ultime sursaut du républicanisme, la société n'est plus une communauté unie dans la recherche d'un bien commun, mais l'arène où s'affrontent des individus aux désirs antagonistes. Comment, par exemple (chap. XvII), définir la justice sans référence à la notion de mérite, mais uniquement, comme le font John Rawls et Robert Nozick (ici rapprochés), comme une théorie de la distribution de ce qui est dû, c'est-à-dire des biens externes, et sans cette notion des biens internes à une pratique?

Nous sommes donc bien «après la vertu », mais MacIntyre affirme finalement son optimisme à l'égard d'une possible concurrence de l'individualisme libéral par l'aristotélisme. Il achève en précisant sa conception de l'historicisme en morale : un fonctionnement similaire à l'histoire des sciences évite certes le relativisme, mais MacIntyre a d'après nous trop tendance à voir des « vaincus » et des vainqueurs en philosophie, parfois au prix de simplifications ou d'interprétations hâtives (c'est notoire à propos du prétendu «test » de Kant, p. 46).

Gabrielle RADICA

Catherine MAIRE, De la cause de Dieu à la cause de la nation. Le jansénisme au ${ }_{\text {XVIII }}^{e}$ siècle. Paris, Gallimard, 1998. $14 \times 22,5,717$ p., bibliogr., index (Bibliothèque des histoires).

Il ne faut pas s'y tromper : contrairement à ce que pourrait laisser supposer le sous-titre, ce livre n'intéressera pas uniquement ceux que passionnent les figures méconnues du diacre Paris, de l'abbé Duguet ou d'Adrien Le Paige, que ce livre s'emploie particulièrement à tirer de l'oubli.

L'ampleur du projet et des thèses soutenues dans cet ouvrage mérite en effet d'être saluée. Elle est le résultat d'une série de révélations et d'une succession de 
mises en contexte qui en élargissent considérablement l'objet: si le jansénisme révèle l'enjeu religieux de la Révolution française, il doit être à son tour analysé en fonction d'un contexte encore plus large, le statut du rapport entre l'Église et l'État, lui-même indice du rapport entre l'homme et Dieu, question centrale de notre modernité, rendue problématique depuis que la Réforme en a bouleversé les termes. Les liens entre ces divers niveaux d'analyse sont précisés dans l'introduction et dans les avant-propos de chacune des trois parties.

Pour l'auteur, qui s'inspire ici des travaux de Marcel Gauchet, le jansénisme propose une compréhension spécifique de la question, centrale, de la grâce, des rapports de l'homme à Dieu : « Il constitue, en un mot, le grand révélateur de la déliaison de l'au-delà d'avec l'ici-bas, qui hante la refondation catholique de la médiation sacerdotale et eucharistique » (p. 14). Les différentes « écoles » jansénistes, au cours des $\mathrm{XVII}^{\mathrm{e}}$ et $\mathrm{XVIII}{ }^{\mathrm{e}}$ siècles, vont toutes tenter de combattre cette déliaison, en cherchant à réinstaurer, chacune à leur manière, l'unité perdue. Ces tentatives ne manqueront pas d'avoir des résonances politiques, rapportées à l'analyse des relations entre l'Église et l'État. Politiquement la déliaison marque, aux termes du parcours que constitue la Révolution, la possibilité d'une indépendance de ces deux dimensions, avènement de la modernité politique. La thèse de Catherine Maire consiste à montrer comment cette modernité a connu une genèse paradoxale, comment le jansénisme a pu contribuer à la subordination de la religion par rapport au politique, menant à terme à leur indépendance. Pour en rendre compte, il est nécessaire de travailler la mémoire du jansénisme, ses transformations, ses évolutions et ses tensions.

On peut rendre compte analytiquement de ce parcours historique en distinguant trois étapes, qui correspondent aux trois parties du livre (il faut toutefois ajouter une première étape, le jansénisme du XVII ${ }^{e}$ siècle, dont rend compte l'introduction). Avec Pasquier Quesnel, le jansénisme allie un christocentrisme d'inspiration tridentine et une «ecclésiologie mystique » qui en est la conséquence logique. L'oratorien exilé apparaît alors comme le double d'Edmond Richer : «On retrouve sur le plan politique le même processus de désassujettissement et d'autonomisation induit par l'absolutisme du Christ» (p. 66). Les tensions créées par cette «crise de la médiation » (résultat du rapport complexe entre une liaison individuelle au Christ alliée à la nécessité de l'Église, complexité dont l'exil même de Quesnel rend compte) ne se révéleront que plus tard, lorsque le compromis élaboré par Louis-Antoine Noailles, que l'auteur décrit comme avant tout soucieux à la suite de Quesnel de promouvoir un gallicanisme épiscopal capable de se démarquer du jansénisme proprement dit, aura été définitivement mis à mal par l'intransigeance des figuristes, issus du séminaire de Saint-Magloire. Ces derniers refuseront de voir dans l'épiscopat le lieu d'union par excellence entre les hommes et Dieu. Cette évolution constitue la dynamique de la première partie, les disciples de Jacques-Joseph Duguet cherchant à rétablir grâce aux figures dans l'histoire, temporellement et horizontalement, le rapport avec un Dieu qui menace toujours de s'absenter du monde. Jean-Baptiste d'Étemare, le principal animateur de ce courant avec Duguet, tirera les conséquences de l'impasse du gallicanisme ecclésiastique pour mettre en place une ecclésiologie particulière, une «ecclésiologie du témoignage» (p. 208). Cette vision de l'Église considère que le dépôt de la vérité n'est conservé que par un petit nombre, à qui il appartient de le sauver en s'inspirant, pour y parvenir, de l'histoire, puisque «le passé est la figure de l'avenir» (p. 89). Se constitue ainsi une matrice heuristique 
qui sera utilisée par la suite dans des contextes fort différents. Le thème du martyr de la vérité devient central, revisitant à l'envi l'histoire du monastère de Port-Royal.

Cette conception du rôle du petit nombre des défenseurs alliée à l'analyse des signes historiques du dessein divin se transformera en véritable projet didactique, en machine de propagande lors de l'épisode des convulsionnaires de Saint-Médard, manifestation exemplaire de la deuxième partie trouvant les signes de Dieu à nouveau inscrits dans la réalité sensible des convulsions et des corps. Le «moule intellectuel créé par le jansénisme » (p. 533) se met alors en place, instaurant un paradoxe, une tension qui ne cessera dès lors de miner le jansénisme: l'impératif d'union, au nom duquel œuvre le «petit nombre », se mue en principe de dissociation et de division au sein même du catholicisme, les convulsions étant rejetées par la majorité de l'épiscopat. Le rôle de martyr de la vérité en vient alors à structurer le projet même du jansénisme.

Le thème de la défense de la vérité, que le figurisme a mis au centre du jansénisme, se transporte ensuite dans un contexte plus politique, évolution caractéristique du troisième moment du jansénisme au XVIII ${ }^{\mathrm{e}}$ siècle : à partir de 1765 , dans le milieu des avocats, "l'influence de l'ecclésiologie figuriste est manifeste dans cette autoproclamation des nouveaux "défenseurs de la vérité" qui entendent prendre la relève de l'épiscopat défaillant» (p. 383). Les évêques ayant failli à leur tâche, ce sont les avocats qui prennent en charge la défense de la vérité catholique, principalement contre la cabale jésuite. Puis, cette défense du dépôt de la vérité se transformera petit à petit en défense du dépôt des lois. Les parlementaires commencent en effet par poursuivre la tâche religieuse des avocats; mais le caractère religieux finit par disparaître au moment de la bataille contre le projet de René-Nicolas de Maupeou, au profit d'une défense du rôle politique du Parlement : «[...] le moule janséniste est brisé. Mais cela ne veut pas dire que la dynamique figuriste est épuisée » (p. 522). Il est bien entendu impossible de rendre compte ici des détails de l'analyse de cette "politisation de la querelle». Le personnage principal en est Louis-Adrien Le Paige : il sera celui qui tentera, sur un terrain politique, de maintenir «l'union mystique entre le Monarque et la Nation» (p. 426), comme les convulsionnaires avaient tenté de figurer l'unité ontologique perdue. Qu'un tel défenseur de l'absolutisme, au nom de la signification religieuse de ce dernier, ait pu contribuer à creuser la distance entre le roi et la nation incarnée dans le Parlement, dépôt des lois, n'est pas le moindre paradoxe de l'histoire du jansénisme. L'analyse historique se termine par l'étude de la Constitution civile du clergé, que Maire lit comme l'aboutissement des tensions propres au jansénisme : ses tentatives de réinstauration de l'unité ontologique débouchent finalement, comme chez Richer, sur une défense de la subordination du religieux au politique.

Maire souligne, à de nombreuses reprises, combien le jansénisme n'existe que comme création continue de sa propre mémoire. «Le jansénisme n'existe qu'en mouvement », il faut prendre en compte nécessairement « la règle de transformation» (p. 375) sans laquelle il serait impossible de le comprendre. L'objet de ce livre consiste justement à suivre ces évolutions, au-delà de leur apparence paradoxale; son intérêt réside bien dans l'établissement de ces liaisons à la fois synchronique (pour chaque auteur) et diachronique (en suivant le gallicanisme, le jansénisme ou le figurisme tout au long $\mathrm{du} \mathrm{xVIII}^{\mathrm{e}}$ siècle). Toutefois, cette double 
systématicité n'apparaît pas toujours évidente. Comment, par exemple, comprendre la filiation entre le figurisme d'Étemare et le jansénisme d'Arnauld et de Pascal, qui recommandait de lutter contre les «trop grands figuristes »? Comment comprendre le figurisme de Le Paige, qui semble ne plus être qu'une vision de la perpétuité de la foi, alors qu'il constitue une véritable exégèse biblique pour Étemare? Quel est le lien entre ce figurisme et ses positions politiques quant au rapport entre Église et État? Les contenus dogmatiques des notions de figurisme, de jansénisme, de gallicanisme évoluent et changent au cours du siècle. En conserver un usage censé être heuristique ne devient-il pas alors problématique? Un tel usage ne risque-t-il pas d'être plus trompeur qu'éclairant? Le gallicanisme, composé de richérisme, régalisme et épiscopalisme, peut-il encore servir d'outil d'analyse en tant que tel? De plus, le caractère systématique de l'interprétation générale de l'avènement du processus de sécularisation centré autour de la figure de Le Paige laisse également parfois dubitatif : son influence permet-elle vraiment d'expliquer l'anticléricalisme de la Révolution, ainsi que la Constitution civile du clergé?

Toutefois, il va sans dire que ces remarques n'obèrent en rien l'intérêt que l'on prend à lire cette thèse. Son mérite consiste, de manière souvent magistrale et toujours suggestive, à décrire le travail de la mémoire qui définit le jansénisme ainsi que la genèse non-linéaire, paradoxale même de la modernité. La part qu'y prit le jansénisme se lit tant au niveau ontologique (dans la tension instaurée entre le monde et un Dieu absent qu'il faut figurer) que dans les conceptions politiques (à travers, en particulier, la «mystique de l'État» de Le Paige, pour qui le Parlement témoigne auprès du monarque de la pérennité de l'unité de la nation), cette analogie témoignant encore de la gloire de Dieu. Cette thèse souligne une nouvelle fois, s'il en était besoin, combien les événements historiques échappent à toute détermination et à toute explication simpliste et linéaire. L'enjeu nécessaire de globalisation l'emporte alors largement sur les risques inhérents à toute systématisation.

Nicolas PIQué

Pierre Chaunu, Madeleine Foisil et Françoise de Noirfontaine, Le Basculement religieux de Paris au XVIII ${ }^{e}$ siècle. Essai d'histoire politique et religieuse. Paris, Fayard, 1998. 15,4 × 23,4, 624 p., bibliogr., index (Centre de recherches Roland-Mousnier, université de Paris IV-Sorbonne).

Comment Paris, citadelle du catholicisme de la Contre-Réforme, peut-elle « basculer » et devenir, autour de 1792, et sous les coups de boutoir de la Commune, un ardent foyer de déchristianisation? Chacun garde en mémoire la tumultueuse séance du 17 brumaire 1793 au cours de laquelle l'évêque de Paris, Jean-Baptiste Gobel, au milieu de fraternelles accolades, vient déposer sa croix et son anneau, symboles de superstition pour se coiffer du bonnet rouge. Seul Grégoire, l'évêque de Blois, de forte imprégnation janséniste, résiste ce jour-là au triomphe de la Raison révolutionnaire. Comment donc expliquer ce prodigieux choc culturel? C'est la question qui anime l'équipe d'historiens confirmés et de jeunes chercheurs qui, autour de Pierre 
Chaunu, s'est penchée sur l'histoire du diocèse de Paris au siècle des Lumières. Le présent livre s'inscrit dans une continuité : il fait suite à l'enquête menée dans $L a$ Mort à Paris (Paris, Fayard, 1978) et trouve des points d'appui dans l'analyse des trois mille foyers parisiens de la regrettée Annick Pardailhé, La Naissance de l'intime (Paris, PUF, 1988). Quarante-huit mémoires de maîtrise, DEA ou thèses cités en ouverture témoignent de l'ampleur des champs couverts comme de l'insatiable curiosité du maître d'œuvre.

Qui faut-il donc incriminer dans ce «basculement »? En vérité, tout le monde semble responsable: Voltaire, c'est bien sa faute, mais aussi celle des jansénistes, des Jésuites, des parlementaires, du clergé, du roi... Reprenons en suivant le plan proposé par les trois auteurs qui offrent trois regards convergents à partir de sources qui se complètent et de démonstrations qui s'emboîtent.

Chaunu s'attache aux fondements de la crise; il décrit ses racines ontologiques au plus profond de la culture chrétienne, puis retrace un vibrant tableau de l'expansion du gallicano-jansénisme, dans une constante perspective d'histoire comparée : «Le jansénisme c'est la modalité française, après l'échec de la réforme humaniste, dans le cadre d'un très, d'un trop grand État, c'est un choix de sensibilité qui sauve, qui évite de sacrifier ce qu'un choix plus radical aurait condamné [...] le gallicanojansénisme serait-il l'anglicanisme à la française?» (p. 85).

Françoise de Noirfontaine dresse un tableau précis, informé, minutieux du conflit janséniste qui se déploie sous Louis Antoine de Noailles, archevêque de Paris de 1695 à 1729, et semble se rétracter sous Charles Gaspard Vintimille du Luc qui lui succède. Les négociations au plus haut niveau entre Paris et Rome sont finement analysées, mais apparaissent, presque au jour le jour, les actions des curés parisiens qui contestent la bulle Unigenitus. Les Nouvelles ecclésiastiques, journal janséniste qui couvre tout le siècle à partir de 1728 , constituent une source fiable. Il s'agit certes d'une œuvre de propagande, mais les rédacteurs n'hésitent pas à corriger d'éventuelles inexactitudes. Pour avoir confronté certains récits des Nouvelles aux sources policières, je ne puis que confirmer cette appréciation (voir Jansénismes et Lumières. Pour un autre XVIII ${ }^{e}$ siècle, Paris, Albin Michel, 1998). Évêques, curés, parlementaires, avocats apparaissent tour à tour dans ces pages définitives. Le bilan de la reconquête parisienne par les autorités antijansénistes demeure «mitigé ». Certes, autour de 1740, une génération janséniste disparaît et les curés constitutionnaires (favorables à la bulle ou constitution Unigenitus) qui les remplacent, mènent de brutales campagnes de normalisation, mais un «noyau dur» se maintient et la violence de la répression trouble de nombreux chrétiens : « À Saint-Roch, quand Brillon prit possession de sa cure, neuf des quinze confesseurs refusèrent d'aller à l'archevêché demander le renouvellement de leurs pouvoirs puisqu'ils savaient leur cause perdue d'avance. Quelques-uns de ces confesseurs exerçaient leur ministère depuis plus de vingt ans, et le départ de ces hommes pieux et charitables bouleversa bon nombre de leurs paroissiens » (p. 239). Nous sommes là au cœur de la spécificité française du jansénisme, tourné vers une active pastorale. Par leurs actions charitables, leurs réseaux d'entraide, leur dynamisme en matière éducative (il faut que les humbles et les femmes même puissent lire la Bible), leur appel constant au militantisme chrétien, les jansénistes bénéficient d'un surprenant enracinement populaire, notamment à Paris.

Madeleine Foisil poursuit cette passionnante et foisonnante histoire « au temps de l'archiépiscopat de Christophe de Beaumont (1746-1781) ». Le nouvel archevêque 
est associé à la grande querelle des refus de sacrement qui transforme la nature de l'opposition janséniste et lui donne, bien involontairement, une popularité nouvelle. Refuser les derniers sacrements, et donc l'enterrement en terre consacrée, à ceux qui ne s'étaient pas confessés à un prêtre «constitutionnaire » n'est pas une nouveauté en soi, mais l'encouragement, le développement, la systématisation de cette pratique exclusive dans la capitale des Lumières relève de la faute. Foisil éclaire fort bien l'intransigeance de l'archevêque, dont la probité et les qualités humaines ne sont pas contestables. De petite noblesse provinciale, sans prestige particulier, rien ne prédisposait Beaumont à une telle carrière, d'où certainement beaucoup de raideur et de maladresse. Une affaire «privée » rend compte de cette psychologie complexe. En 1773, l'archevêque demande à l'avocat au Parlement Gabriel Brizard une étude généalogique destinée à valoriser ses origines familiales; mais le travail terminé, le livre fait, Beaumont en stoppe la diffusion par crainte des réactions de ses adversaires. Brizard, furieux, écrit un mémoire pour défendre son travail, et se trouve le premier à attaquer son commanditaire velléitaire : «Il pouvait se faire que ses ennemis ne regardassent pas comme un acte d'humilité la fantaisie qu'il avait de faire l'histoire de sa maison et que les gens à scrupules jugeassent que les sommes détournées eussent été mieux employées en les versant dans le soin des pauvres » (p. 249). Ayant éclairé la personnalité si décisive de l'archevêque, Foisil analyse le temps fort de la crise des billets de confession de 1751 à 1754, les exils de 1754 à 1764, les relations avec les philosophes, l'état ecclésiastique de Paris au temps de la commission des Réguliers, la chute des Jésuites. Outre les Nouvelles ecclésiastiques, « la seule presse libre de l'époque » (p. 252), Foisil utilise avec sagacité les témoins prolixes que sont Argenson, Luynes, Barbier, ainsi que le précieux journal du libraire Simeon Prosper Hardy, qui de 1764 à 1789 nous livre 4082 pages d'une écriture dense et régulière; curieux de tout, ce libraire est janséniste, et comme tout bon janséniste récuse ce terme péjoratif, inventé par les Jésuites pour désigner les seuls vrais défenseurs de la Tradition.

Pierre Chaunu reprend la plume pour analyser le « défi du siècle ». Il mesure, en suivant les analyses proposées par Jean-Pierre Bardet (judicieusement reproduites en annexe) les critères démographiques reconstitués du «basculement » religieux. Il s'attaque, non sans une certaine sympathie, à l'immense pouvoir du roi Voltaire, avant de reprendre le cours de l'histoire en consacrant un chapitre à l'épiscopat de monseigneur de Juigné. L'engagement de l'Église et de son archevêque contre l'édit de tolérance à l'égard des protestants est qualifié de «faux pas ». Il faut souligner que, dès les années 1780, les Nouvelles ecclésiastiques font, elles, campagne pour la tolérance civile.

Passablement malmenés par Chaunu, les jansénistes retrouvent dans la très belle postface (dédiée à Alphonse Dupront et à François Furet) un peu de leur sombre grandeur. Ils ne sont pas, et loin de là, les seuls chantres d'un rigorisme paralysant : «Les formes les plus âpres du rigorisme, les plus étouffantes, sont véhiculées par le molinisme » (p. 538). Chaunu cite la prière de Jansenius, récitée deux fois au moins par semaine, avant la communion par les religieuses de Port-Royal et s'émerveille de la capacité d'évolution du jansénisme, à partir du cas de l'abbé d'Étemare si bien cerné par Bruno Neveu. Décidément, les jansénistes ne sont pas les premiers coupables. Un mouvement si divers, si fluctuant, si contradictoire, tellement éclaté, ne peut à lui seul rendre compte de la spécificité française, même s'il constitue par 
sa longue durée et par son implantation sociale un observatoire privilégié. La radicale coupure entre le christianisme et les Lumières, coupure soigneusement entretenue et pratiquement constituée en dogme culturel, est à l'origine de ce que Chaunu appelle « une laïcité d'exclusion », c'est-à-dire d'une neutralité de l'État, qui loin d'être bienveillante, ne tolère le religieux que comme un mal nécessaire : « Aux laïcités organisatrices de la pluralité s'opposent la laïcité d'exclusion » (p. 16). Au travers des différents régimes, monarchiques, jacobin, napoléonien, républicains, le culte de l'État s'impose, en France, au détriment de toute diversité. Il serait passionnant de voir comment évoluent ces deux formes de laïcité... Il me semble que celle des pères fondateurs, de Ferdinand Buisson notamment, ne relève pas de l'exclusion. Mais c'est au cœur de la période moderne que Chaunu cherche les racines de cette fondamentale anthropologie politique, et il les trouve dans la révocation de l'édit de Nantes qui « coule durablement la France dans le plomb du mythe d'une unité artificielle persécutrice» (p. 539). Longtemps impitoyable face à la minorité protestante, la monarchie ne peut tolérer l'existence de sensibilités catholiques diverses. Lorsque tardivement et timidement, l'État, lui-même imprégné par les Lumières, commence à évoluer, l'Église majoritaire se fige, elle, dans la résistance et maintient la lutte contre la tolérance. Les clés de la déchristianisation révolutionnaire sont aussi à rechercher de ce côté : « basculement », non pas au sens d'un brutal et irréversible effondrement, mais tragique jeu de bascule, sans cesse renouvelé, passage d'une totalité à une autre, blocage structurel devant la pluralité.

Monique CotTret

Jean Barbeyrac, Écrits de droit et de morale. Prés. par Simone Goyard-Fabre. Paris, Centre de philosophie du droit (Paris II-CNRS-URA 956), 1996. $15,5 \times 24,283$ p., index.

Jean Barbeyrac (1674-1744) est surtout connu de nos jours pour les traductions et les commentaires qu'il a rédigés au début $\mathrm{du}_{\mathrm{XVIII}}{ }^{\mathrm{e}}$ siècle des œuvres fondamentales de Grotius, de Pufendorf et, à moindre degré, de Cumberland. Aussi est-ce une excellente idée de publier quelques-uns de ses propres ouvrages qui permettent de mieux comprendre cet érudit modeste, modéré, courtois, modèle du monde académique. Le «Mémoire sur la vie et sur les écrits de Mr Jean Barbeyrac, écrit par luimême » a tous les charmes du curriculum vitce, mais suivent trois discours académiques qui nous plongent dans l'univers des Lumières : le «Discours sur l'utilité des lettres et des sciences par rapport au bien de l'État» de 1714, le « Discours sur la permission des loix » de 1715, le « Discours sur le bénéfice des loix » de 1716, un texte polémique, le «Jugement d'un Anonyme avec les réflexions du traducteur » de 1716 et la préface du Traité de la morale des Pères de l'Église de 1728.

Dans une longue et savante introduction, Simone Goyard-Fabre rappelle les principaux événements qui ont marqué la vie de ce savant. Jean Barbeyrac est né à Béziers, son père était pasteur de l'Église réformée. La révocation de l'édit de 
Nantes en 1685 contraint la famille à s'exiler à Lausanne; il y poursuit de brillantes études, interrompues en 1690-1691 par la mort de son père, puis de sa mère. Chef de famille, il se débat alors dans les difficultés financières et nourrit (fort mal) son frère et ses sœurs à partir de maigres subsides et de bourses qu'il réussit à décrocher. En 1697, l'électeur Frédéric le prend sous sa protection et sa situation s'améliore : il enseigne au collège français de Berlin et fonde sa propre famille. C'est là qu'il commence à travailler à la traduction du De jure naturae et gentium de Pufendorf, tâche immense qui sera achevée en 1703 et publiée en 1706 : en 1707, paraîtra la traduction du De Officio hominis et civis, en 1709 le Traité du jeu... L'autorité de Barbeyrac est désormais reconnue, et en 1711 il est nommé à l'académie de Lausanne au sein de laquelle il enseignera le droit jusqu'en 1717. On lui proposa ensuite une chaire à l'université de Groningue, où il passa vingt-quatre ans, occupant à trois reprises la charge du rectorat.

Goyard-Fabre souligne combien la réflexion sur le droit naturel se situe au cœur de l'œuvre de Barbeyrac, mais elle remarque également combien historiens et commentateurs ont eu tendance à trop schématiser cette question en embrigadant « tous les auteurs de l'école du droit de la nature et des gens sous la bannière d'une modernité dont Grotius et Descartes auraient posé les premiers jalons» (p. 65). Loin de céder à cette tendance simplificatrice, Barbeyrac lui-même a vu les contradictions entre les grands auteurs qu'il traduisait : «Barbeyrac a fort bien perçu au contraire l'ambivalence de la théorie jusnaturaliste tiraillée entre tradition et novation; les notes et commentaires de ses traductions montrent combien la doctrine du droit naturel est éclectique puisqu'en elle se retrouvent les influences mêlées de Platon et du stoïcisme, d'Aristote et du thomisme, de la patristique chrétienne et de la Réforme, du nominalisme d'Occam, de l'humanisme renaissant...; ses propres écrits et, notamment, sa réfutation de Leibniz, enseignent que, selon les auteurs, les mêmes thèmes sont traités en obéissant à deux inspirations philosophiques divergentes » (p. 65).

À ce titre, Grotius et Pufendorf célébrés comme les pères communs de l'école du droit naturel semblent plutôt des frères ennemis. Leur descendance accentue les contradictions : "Ou bien le droit naturel défini par Grotius comme expression de la raison devient l'un des philosophèmes-clefs autour duquel se construira la pensée légaliste des Lumières; ou bien, considéré comme l'expression de la volonté d'un Supérieur, il inspire un courant libéral qui n'est pas étranger à la philosophie de John Locke. Barbeyrac, avec lucidité, a déchiffré dans les textes les enjeux éthiques de cette alternative. » Proche de Pufendorf, Barbeyrac redoute cependant les excès d'un humanisme par trop rationaliste qui conduirait l'homme à une trop grande autonomie. Il pense que « les règles du droit naturel sont celles que Dieu a établies et qu'il enseigne aux hommes par la lumière de la raison » (p. 66); Goyard-Fabre souligne avec raison la parenté de cette conception avec celle du juriste, ami de Pascal, Jean Domat. C'est en fait une tendance que l'on retrouve chez nombre de jansénistes, qualifiés de «centristes » (voir Jansénisme et politique, textes choisis et présentés par René Taveneaux, Paris, Colin, 1965, p. 89) qui, avec Arnauld et à sa suite, ont été marqués par le thomisme et acceptent la possibilité d'un progrès dans l'ordre temporel. Domat effectivement, mais également dom Gerberon proposent des définitions semblables de la loi naturelle. Il faudra cependant attendre la fin du XVIII ${ }^{\mathrm{e}}$ siè- 
cle, les années 1780, pour qu'elles atteignent une représentativité plus grande parmi les jansénistes.

Monique CotTreT

Michel Espagne, Les Juifs allemands de Paris à l'époque de Heine. La translation ashkénaze. Paris, Presses universitaires de France, 1996. $15 \times 21,7,261$ p., bibliogr., index (Perspectives germaniques).

Le célèbre poète Heinrich Heine, Juif allemand par ses origines, vécut à Paris de 1831 jusqu'à sa mort, en 1857. Le rapport entre ses origines juives et son œuvre a souvent été étudié — rappelons seulement ici l'étude magistrale de Siegbert S. Prawer, germaniste d'Oxford, Heine's Jewish Comedy (Oxford, Clarendon, 1983). L'approche de Michel Espagne dans ce livre est différente : il examine la situation complexe des Juifs allemands à Paris, à l'époque de Heine, c'est-à-dire de l'époque de la monarchie de Juillet jusqu'au Second Empire avec, bien sûr, quelques aperçus avant et après cette période. Heine, l'un des représentants les plus éminents de la présence juive allemande à Paris $\mathrm{au} \mathrm{XIX}^{\mathrm{e}}$ siècle, demeure, bien évidemment, l'une des références fondamentales tout au long de cette belle étude, qui constitue ainsi une digne contribution au bicentenaire de la naissance du poète, lequel fut célébré en 1997.

Mais l'intention de l'auteur dans ce livre est plutôt d'étudier le contexte dans lequel Heine vécut à Paris ou, en d'autres termes, toute la vie sociale et intellectuelle des Juifs allemands de cette époque. Dès l'introduction, Espagne nous rappelle que le séjour de Heine en France coïncide pratiquement avec la période durant laquelle les Juifs allemands marquèrent le plus fortement la culture parisienne : la période qui s'étend de 1830 à 1859 , depuis le «moment où la France souhaite contrôler la formation des élites juives en fondant une école rabbinique à Metz à celui où elle transfère cette école à Paris pour l'arracher aux influences germaniques » (p. 18). Il souligne aussi que le réseau formé par les amis de Heine - les hommes de lettres, le milieu artistique des musiciens et des acteurs, les réfugiés politiques, mais aussi les banquiers aisés, etc. - constitue « l'un des meilleurs fils directeurs à partir duquel une exploration du judaïsme allemand à Paris peut être entreprise » (p. 19).

L'introduction précise la tâche exacte assignée à l'étude, mais donne aussi quelques informations démographiques très révélatrices : la population juive de Paris augmenta fortement durant le $\mathrm{XIX}^{\mathrm{e}}$ siècle, de quelque 500 à 800 personnes à la fin du $\mathrm{XVIII}^{\mathrm{e}}$ siècle jusqu'à 40000 en 1880 . Par rapport à l'ensemble de la population parisienne, la proportion de Juifs augmenta aussi de 0,01 à $2 \%$. Il est démontré ici, de façon tout à fait convaincante, que cette augmentation ne fut due ni à un apport de Juifs avignonnais ni à un apport de Juifs portugais, mais résulta majoritairement d'une arrivée de population ashkénaze (p. 9). Dès son introduction, Espagne se voit bien évidemment confronté à la question de l'identité des Juifs ashkénazes de Paris ou, pour exprimer cela plus simplement, à la question de savoir selon quels critères il est possible de définir l'appartenance à ce groupe : se limite-t-on à une définition 
juridique étroite, par exemple à l'inscription sur les listes du Consistoire? Une telle façon de procéder exclurait un grand nombre de Juifs et, souvent, les cas les plus intéressants. Espagne se décide plutôt pour une définition plus large de la « vie communautaire », à la Leo Baeck (L'Essence du judaïsme, Paris, Presses universitaires de France, 1993, p. 360). L'introduction évoque aussi le paradoxe que présente la situation des Juifs de France à l'époque : la partie ashkénaze et germanique du judaïsme français, nous rappelle Espagne, apparaît à la fois comme la plus pauvre et la plus marquée par le souvenir d'anciennes persécutions - et comme la plus dynamique, celle qui fournit les représentants les plus marquants de l'identité communautaire. Comment expliquer ce paradoxe? Le livre apporte beaucoup d'éléments de réponse à cette question.

Dans les chapitres qui suivent, Espagne examine l'un après l'autre les différents groupes de Juifs allemands à Paris : ceux qui contribuèrent à l'introduction et à la propagation en France de la pensée de Mendelssohn, puis à celle de la Science du judaïsme (p. 21-56); les hommes de lettres et les journalistes (p. 57-83); les compositeurs, les musiciens et les comédiens (p. 85-109 et 164-169); les groupes d'opposition politique, qualifiés ici de «messianiques », qui étaient en tout cas souvent néohégéliens et en faveur du saint-simonisme (p. 111-134); les banquiers, dont l'ascension sociale fut souvent fulgurante (p. 135-156); les savants, hommes de science et philologues, les membres de professions libérales comme les médecins tous ces groupes sont analysés en détail et avec beaucoup de discernement. Notons encore que les femmes juives ne sont pas négligées (p. 157-172). Espagne décrit les séjours parisiens de Rahel Varnhagen/Levin et Dorothea Mendelssohn/Veit/Schlegel, mais aussi les parcours fort différents de la célèbre actrice Rachel [Félix] ou de l'écrivain Fanny Lewald. Les convertis, qui furent souvent poussés à accomplir le pas vers la conversion, ne sont pas non plus exclus par Espagne - parce qu'ils font tout de même partie de la vie communautaire (p. 173-189). Il me semble de bon augure que l'auteur ne partage pas un préjugé trop souvent entretenu par des gens issus de circonstances plus heureuses que leurs aînés et pourtant prêts à les condamner. Le petit colporteur ou chiffonnier ashkénaze, cette figure sans doute caractéristique d'une certaine situation juive en France au $\mathrm{XIX}^{\mathrm{e}}$ siècle, n'est pas absent du livre. L'auteur démontre au contraire comment cette classe se transforma pendant la période étudiée, rejoignant par là la classe moyenne de la population française. Mais ce fut sans doute aussi le sujet du livre qui en détermina les priorités thématiques : si l'on veut analyser l'influence des Juifs allemands sur la vie culturelle parisienne, il faut bien mettre l'accent sur ceux «qui ont exercé le rayonnement le plus évident sur leur milieu d'insertion», et donc inévitablement sur « une sorte d'élite du judaïsme ashkénaze » (p. 17).

La lecture du livre peut être fortement recommandée non pas seulement à tous ceux qui s'intéressent aux différents cercles de Juifs allemands à Paris que fréquentait Heine, mais aussi, et ceci est sans doute beaucoup plus fondamental, à tous ceux qui veulent comprendre le rôle des Juifs ashkénazes dans la constitution de la culture parisienne. Par-delà ces aspects savants, destinés à la communauté scientifique, le livre a aussi un côté par lequel il touche à une actualité politique brûlante : par sa contribution à l'analyse de la façon dont s'est constituée l'identité culturelle parisienne - à partir de groupes multiples - ce livre réduit au domaine idéolo- 
gique les prétentions d'une «identité nationale» repliée sur elle-même et autosuffisante.

Norbert WASZEK

Étienne Foullloux, Une Église en quête de liberté. La pensée catholique française entre modernisme et Vatican II (1914-1962). Paris, Desclée de Brouwer, 1998. $14 \times 21,5,327$ p., index (Anthropologiques).

Le nouveau livre d'Étienne Fouilloux, spécialiste reconnu de l'histoire du catholicisme au $\mathrm{Xx}^{\mathrm{e}}$ siècle, développe et précise la contribution fournie par l'auteur au volume XII de l'Histoire du christianisme (Paris, Desclée/Fayard, 1990, p. 506522). Dans un organisme religieux tel que le catholicisme, d'implantation universelle et fortement centralisé, il est toujours indiqué de situer une histoire régionale dans un contexte international, projet que s'efforcent de réaliser les volumes de l'Histoire du christianisme. Pour autant, et quoique limité à la France, le présent volume garde une portée générale. En effet, la récente histoire du catholicisme français a été spécialement marquée par de durables et profonds conflits avec les autorités romaines, dont l'enjeu, en deçà des points de doctrine débattus, porte sur la liberté des intellectuels catholiques. La crise moderniste (1893-1907) amena sous la plume d'Alfred Loisy, de ses amis et de ses défenseurs, une première formulation du droit à la libre recherche au sein de l'Église catholique. On sait ce qu'il en advint : les lourdes condamnations portées contre les exégètes, historiens et philosophes catholiques amalgamés sous le nom de «modernistes » par l'encyclique Pascendi de Pie X (1907) furent aggravées par une série de mesures disciplinaires destinées à aligner le catholicisme français sur la théologie romaine. Celle-ci était d'autant mieux armée pour surveiller les catholiques d'outre-monts qu'elle comptait parmi ses membres les plus éminents des Français influents et combatifs, professeurs dans les universités romaines ou membres de Congrégations chargées du gouvernement de l'Église.

Le combat pour la liberté de pensée et de parole dans l'Église se sépare difficilement du combat pour la démocratie et les droits de l'homme dans la société politique. C'est pourquoi, explique Fouilloux, la revendication de liberté posée par les intellectuels catholiques français ne pouvait être ressentie à Rome que comme une menace pour la politique intransigeante du Saint-Siège. Intransigeance qui s'exprime d'abord comme une lutte contre la sécularisation des sociétés et contre la perte, pour le catholicisme, de sa position privilégiée qui fait craindre aux autorités de l'Église le développement de l'indifférence religieuse. Intransigeance qui s'exprime ensuite, spécialement sous le pontificat de Pie XII, comme un refus de toute complaisance envers le marxisme et ses réalisations politiques, au nom de la liberté religieuse.

En France, la position des catholiques partisans de l'ouverture doctrinale est d'autant plus difficile à tenir, dans les années 1920, que l'Action française jouit d'un grand prestige parmi l'intelligentsia catholique de notre pays, clercs et laïcs confon- 
dus. La critique des mœurs parlementaires, la défense des valeurs morales et religieuses portées par la tradition, la stricte obéissance à la discipline catholique sortie renforcée de la définition de 1871 (relative à l'infaillibilité du pontife romain et à sa juridiction universelle), toutes ces attitudes se renforcent l'une l'autre et repoussent dans l'ombre les tentatives des intellectuels catholiques soucieux de reprendre à nouveaux frais les questions laissées ouvertes par la crise moderniste. C'est pourquoi la très ferme intervention de Pie XI, prélat par ailleurs autoritaire et méfiant vis-à-vis de l'innovation doctrinale, contre l'Action française en 1926 fait l'effet d'un coup de tonnerre. L'obéissance à la discipline catholique va jouer ici en faveur $\mathrm{du}$ «mouvement ». Car non seulement, elle conforte le « second ralliement », c'està-dire la pleine acceptation par les catholiques du régime républicain, dont la laïcité s'est modérée. Mais elle libère la philosophie catholique la plus officielle, celle qui se veut thomiste, d'un alignement rigoureux sur les positions du catholicisme intransigeant. Le cas de Jacques Maritain, auquel l'auteur consacre d'excellentes pages, est ici très éclairant (p. 57-65, 80-84 et 112-119). En second lieu, malgré le climat de surveillance doctrinale encore sévère sous Pie XI, un certain printemps intellectuel va fleurir dans l'Église de France. En témoignent des initiatives comme la création de la revue La Vie intellectuelle (1928) et de la collection théologique «Unam Sanctam », tandis que l'œuvre d'Henri Bergson suscite une grande attention dans le public catholique cultivé.

Mais c'est la Seconde Guerre mondiale qui, paradoxalement, et en dépit des difficultés connues par l'édition, va donner au catholicisme français une plus grande autonomie : les communications avec Rome sont en effet difficiles. C'est pourquoi les années 1939-1945 et les suivantes s'enrichissent d'initiatives théologiques et pastorales. Dans le premier de ces domaines, Fouilloux privilégie l'action des deux ordres religieux porteurs d'une longue tradition de recherche: les Jésuites et les Dominicains. Ceux-ci, principalement entraînés par deux grands leaders, les pères Marie-Dominique Chenu et Yves Congar, rénovent l'étude du thomisme, branchent la recherche théologique sur les problèmes venus du laïcat, et engagent le catholicisme français dans la voie de l'œcuménisme. Les Jésuites s'investissent soit dans de considérables études de théologie historique, soit dans un renouveau de l'apologétique marqué par la pensée de Maurice Blondel. Dans les années qui précèdent la Seconde Guerre mondiale, ils s'intéressent à la philosophie de Hegel, dont ils vont devenir d'éminents spécialistes, et se donnent ainsi le moyen de pénétrer la pensée marxiste et de la présenter autrement que comme un épouvantail.

Fouilloux écrit dans le détail l'histoire de ces ouvertures et des difficultés qu'elles ne cessèrent de susciter aux Français de la part des autorités romaines jusqu'en 1954. Les plus illustres théologiens français ont en effet connu, à diverses reprises, des interdictions d'enseigner, des déplacements de résidence et jusqu'au désaveu discret mais ferme de l'encyclique Humani generis (1950). Soucieux des nuances nécessaires, l'auteur veille à ne pas transformer son récit en réquisitoire et note les ouvertures effectuées par le Saint-Siège lui-même : il autorise une timide évolution de la liturgie et, surtout, libère en 1943 la recherche de l'exégèse biblique par l'encyclique Divino afflante spiritu. Cependant, l'ensemble des procédures menées contre les théologiens français est présenté par Fouilloux comme dénué d'équité. En particulier, la plupart des condamnations ou des mesures disciplinaires sont décidées sans consultation des intéressés, qui ne peuvent se défendre. Dans tel ou tel cas, 
c'est la pression de l'ambassade de France près du Vatican qui a évité une mise à l'index désastreuse. Le dossier fourni par l'auteur est établi sur une documentation considérable et on ne peut que lui donner acte de cette démonstration. L'inaccessibilité des archives du Saint-Siège après 1922 restreint les sources dont peut actuellement disposer l'historien, mais celui-ci ne porte pas la responsabilité d'une telle limitation de ses investigations.

À la lecture de ce livre, il devient clair que le déroulement du second concile du Vatican a offert aux vaincus des années 1893-1954 une grande revanche, difficilement supportée par les tenants du catholicisme intransigeant, qui ont cherché à en minimiser les effets, en se couvrant de l'autorité d'un pape dont l'expérience historique, celle de la situation polonaise, était tout autre que celle des Français. Par ailleurs, la franchise de Fouilloux ne manquera pas de déplaire aux admirateurs de l'imposante et séculaire Église romaine, et de la sage lenteur avec laquelle elle consent à se réformer; il s'en trouve même parmi les incroyants.

Mais cela dépasse une affaire de goût ou de sensibilité entre divers courants. Car l'historien des doctrines religieuses dans le christianisme ne peut manquer d'observer que la violence de ces conflits tourne autour d'un centre obscur : n'y aurait-il pas eu, dans le système catholique, mutation de la définition et de la fonction de la vérité ? Il paraît en effet évident qu'en acceptant pleinement le droit de chacun à choisir librement la forme de son adhésion religieuse ou son refus de la croyance, en valorisant l'apport théologique et spirituel des autres confessions chrétiennes, voire des religions non-chrétiennes, l'Église catholique a choisi une attitude qui ne pouvait manquer de retentir sur son discours au sujet de la vérité. D'ailleurs, Jacques Maritain avait demandé avec insistance au pape Paul VI, après le second concile du Vatican, la publication d'une encyclique sur la vérité. C'est, en effet, à ce niveau qu'il faudrait désormais travailler pour éclairer, en les replaçant dans la longue durée, les conflits dont Étienne Fouilloux nous rapporte la pénible histoire.

François LAPLANCHE

La Morale des moralistes. Textes recueillis par Jean Dagen. Paris, Honoré Champion, 1999. 16,5 × 24, 245 p., index (Moralia, 2).

L'objectif du volume dans lequel Jean Dagen a recueilli les interventions du colloque «La morale des moralistes » du 9-10 novembre 1994, à la Sorbonne, peut être ramené à l'interrogation suivante : y a-t-il une spécificité de la chose morale ? Si la question dépasse la seule fondation d'un système éthique comme le montre Corrado Rosso, elle ne s'éloigne jamais de celle de la forme que prend l'écriture moraliste. Dans l'avant-propos, Dagen affirme que les moralistes ont en commun un «pouvoir de caractérisation » que les différents conférenciers illustrent, tant par l'exemple de la pratique de la forme brève, que dans celui de la capacité — paradoxale alors de dégager une pensée construite. La Rochefoucauld, «parangon» du moraliste pour Dagen, est légitimement de toutes les communications. Exemplaire pour illus- 
trer cette complétude, à l'intérieur même d'un texte incomplet selon Rosso. Il est au départ d'une tradition qui, jusqu'à Vauvenargues sublimera la rhétorique pour la faire éloquence (Alain Michel), ou bien encore (repris par Oskar Roth) pour traiter de la Morale de la retraite et montrer que ce souci des autres - se retirer du commerce du monde - n'est qu'orgueil et flatterie envers soi-même, ce en quoi l'analyse est morale. Michel Delon, quant à lui, met en perspective la morale des Maximes et son échouage dans les textes sadiens. Il analyse finement comment de l'amour-propre à l'amour de soi et à l'isolisme, autrui devient progressivement un objet, par usure, inversion et/ou filiation paradoxale des formules originelles, ce qu'il appelle une « réanimation criminelle».

Autour de cette image nucléaire gravitent les portraits de ceux que les intervenants ont choisi de présenter dans une tradition - de fond et/ou de forme - ou d'un point de vue plus inattendu. Ce dernier est illustré par le commentaire dont Francine Wild entoure les Historiettes de Tallemant des Réaux. Convaincue qu'on ne peut écrire sur les hommes sans écrire sur l'homme, Wild déchiffre la morale de ce texte dont on ne peut établir s'il est réellement conformiste ou véritablement libre, et dessine le portrait libertin de leur auteur, qui dégage une morale de l'habileté, de la lucidité avisée, toujours entièrement située « au plan de l'humain ». C'est en termes semblables que Jean-Paul Larthomas parle de Shaftesbury, puisqu'il le montre virtuoso de sa propre vie, par insertion mondaine, héroïque et esthétique tout à la fois. Avec Shaftesbury, la morale a conquis et franchi l'espace qui, de Montaigne à Prévost et à Marivaux, correspond à une intériorisation de la religion. JeanFrançois Lecoq, mais aussi et autrement Jean Céard — « Apologétique et morale, de Sebond à Duplessis-Mornay » - explorent cet anthropocentrisme novateur. Si la raison est la mesure de l'homme, au sens aussi où elle peut être sa limite, la morale est circonscrite à la place où l'homme se déplace justement, c'est-à-dire sa conscience, mue par sa volonté et son mérite, la valeur de ses intentions : agir selon ce que les hommes se doivent, et que Lecoq appelle la morale naturelle, après avoir montré ce que les romanciers moralistes du $\mathrm{XVIII}^{\mathrm{e}}$ siècle doivent aux livres de piété $\mathrm{du}_{\mathrm{XVII}}{ }^{\mathrm{e}}$ en ce domaine. Restent trois portraits, Lévesque de Pouilly par Arnaldo Pizzorusso, Chamfort par Margot Kruse, et « le petit moraliste » par Henri Coulet. Que le premier s'applique à montrer l'économie des plaisirs, l'usage équilibré des facultés humaines, que le deuxième occupe une place originale dans la tradition critique et satirique (insuffisance de la lutte contre les passions, nécessité de les anéantir), et que le troisième soit un recours salutaire contre la force de l'absolu et les exigences hors d'atteinte, ce triptyque, à mon avis, suit une ligne commune, qui va de l'estime de soi, en passant par la position de refus, voire de mépris pour l'homme, à l'établissement du sujet moral.

Quant à l'espace réservé dans les textes des moralistes aux différents usages de la tradition, on peut le diviser ainsi : d'une part, celui qui relève du fond et Emmanuel Bury montre la place de l'augustinisme et de l'épicurisme comme force d'opposition au thomisme toujours plus ou moins d'actualité; Philippe Sellier rend compte de cet humus augustinien dans cette "hantise de l'écoulement» qui a permis une écriture des Vanités (Bossuet); mais c'est la fin du cosmos aristotélicien qui coïncide, pour Jean Mesnard, avec la constitution d'une littérature moraliste, par conquête de soi. D'autre part, une évidente tradition formelle, bien connue dans la pratique de l'écriture fragmentaire. Mais celle-ci n'est pas vraiment envisagée pour 
elle-même, pas même par Bernard Beugnot ou Sylvain Ménant qui s'interrogent sur l'opportunité de faire de la morale en poésie, ou d'une morale poétique au XVII ${ }^{\mathrm{e}}$ siècle. En effet, la dissociation du fond et de la forme s'y révèle plus que délicate et les propos d'Alain Michel sur la nature du lien qui va « de la morale latine aux moralistes français » le montrent bien, qui, après avoir marqué la place du stoïcisme notamment, font apparaître que l'efficacité du discours passe par le proverbe, la sententia, le style, la forme dans la continuité aussi des Anciens. Ce que le poétique ajoute à la morale, c'est l'accord de la sensibilité selon Beugnot, une pédagogie du cœur, de la fantaisie et même du rêve selon Ménant, alors que, par la morale, la poésie est innocentée de toute accusation de frivolité. La dimension anthropologique particulière de la morale que décrit Louis Van Delft n'est cependant pas séparable de ce souci de la forme. Il dégage en effet ce qu'elle doit à l'anatomie, dont le modèle et le vocabulaire ont servi le discours sur l'homme. L'anatomie comme analogie du geste incisif, c'est-à-dire de l'écriture fragmentaire, la démonstration est particulièrement pertinente.

Je sépare pour finir les propos d'André Tournon qui, sous le joli titre Le Penseur, le poète et les pigeons, examine les douloureux rapports de la sagesse et de l'amour, pour illustrer et rectifier l'image commune du furor amoris. La fascination amoureuse peut-elle n'être pas inquiète, se demande Tournon, qui, avec l'ironie et la nostalgie du fabuliste, célèbre la quiétude et les plaisirs amoureux quand ils sont distanciés de la sévère morale des moralistes.

Pascale Busson-MARTELLO

Patrick ThIERry, La Tolérance. Société démocratique, opinions, vices et vertus. Paris, Presses universitaires de France, 1997. 11,3 × 17,5, 128 p., bibliogr. (Philosophies, 77).

Si la tolérance est une notion fort sollicitée — et ce d'autant plus en 1998, année de célébration de l'anniversaire de l'édit de Nantes - son sens reste ambigu (estelle condescendance, licence, indifférence, patience à l'égard de l'erreur, voire du vice, ou valorisation des diversités ?) et ses usages contradictoires : prônant la libre discussion, elle autoriserait toutes les opinions, même intolérantes, au risque de se contredire elle-même et de se débarrasser de toute discussion. En donnant toutes les opinions pour équivalentes et en refusant toute limite, la tolérance constituerait par là un «évitement du conflit des moralités ». Il convenait donc de remonter aux sources de l'idée de tolérance, pour en préciser le sens en l'inscrivant dans des stratégies politiques et philosophiques différenciées : tout le parcours tracé par Patrick Thierry met en valeur le passage d'une problématique théologique concernant l'attitude des institutions ecclésiastiques vis-à-vis de l'erreur coupable (hérésie) à une problématique politico-juridique fondée sur la séparation du public et du privé. Entre-temps, la conscience a été constituée en instance autonome divine, pierre de touche de la vérité et fondement d'une conception moderne de la tolérance. L'itinéraire construit par Thierry va ainsi « des voies du salut au secret des alcôves », du 
ciel vers les mœurs et la régulation de la sociabilité, substituant à la question du salut dans le christianisme celle de l'individualisme et de son déploiement dans la sphère du privé. Si la tolérance est d'abord identifiée à une forme de condescendance ou d'indulgence pour une erreur coupable, ne constituant en aucun cas une vertu mais une faiblesse ou un acte de prudence dicté par l'utilité sociale, elle est conçue comme un moindre mal permettant d'éviter les conflits (saint Thomas) sans invalider le recours à la «juste persécution », dans laquelle saint Augustin voyait une violence légitime pédagogiquement féconde. Comment la tolérance a-t-elle pu, dans ce contexte, devenir une vertu dont chacun se réclame et une valeur fondatrice des démocraties modernes? Dans la perspective de Thierry, deux moments opèrent ce passage : la Lettre sur la tolérance de John Locke (1689) et le Commentaire philosophique de Pierre Bayle (1686). Un troisième moment, marqué par De la liberté de John Stuart Mill (1859), placera la tolérance dans une perspective résolument individualiste, articulant les rapports du public et du privé, de l'Etat et des droits de l'individu. L'inscription de l'idée de tolérance dans la tradition anglo-saxonne moderne fournit un éclairage original, enrichi par les travaux antérieurs de Thierry (Essais sur Tocqueville et la société américaine, Paris, Vrin, 1994, et Essais esthétiques d'Adam Smith, Paris, Vrin, 1997).

En construisant sa position sur la sécularisation du domaine public et le transfert du culte dans le privé, Locke fonde la tolérance sur un argument juridique dont la fonction est de séparer l'Église et l'État suivant leurs fins poursuivies et les moyens qui leur sont impartis, mettant un terme à toute une tradition de la « république chrétienne » (Thierry y lit l'influence du pasteur Roger Williams). L'Église est une société parmi d'autres (dont le caractère commun est le volontarisme), et la religion devient une affaire privée. La Raisonnabilité du christianisme oblige néanmoins à nuancer la thèse lockienne dès lors que le christianisme apparaît comme une religion vraie confirmée par la raison, ou bien comme une religion dans laquelle la raison retrouve ses propres conclusions obtenues sans révélation. Tandis que la Lettre sur la tolérance exclut de la tolérance les athées et les catholiques, la Raisonnabilité du christianisme fait de la religion établie le garant de la paix et de l'unité civile, et non plus une simple affaire privée. La position de Locke, qui se trouvait déjà en partie chez Machiavel, se retrouvera plus tard dans l'idée d'une religion civile chez Rousseau.

Il n'en reste pas moins que la position lockienne, suivant Thierry, demeure insuffisamment fondée si elle ne prend pas appui sur la thèse de la liberté de conscience, ou du caractère divin de celle-ci (tel que le défend Bayle). On peut être plus réservé sur ce choix théorique dans la mesure où, d'une part, l'ouvrage de Bayle est antérieur à celui de Locke, et où, d'autre part, pour ce dernier, la liberté de conscience ne doit pas faire obstacle au devoir d'obéir aux lois du magistrat, même si la conscience est reconnue comme une instance divine à laquelle chacun a le devoir absolu d'obéir. Tout le problème de la Lettre sur la tolérance est en effet d'accorder ces deux exigences en fondant la tolérance non pas seulement sur l'argument théologique de la liberté de conscience (on pourrait ajouter : et du caractère non-volontaire de nos convictions), mais avant tout sur l'argument politique et juridique de la séparation de l'Église et de l'État. C'est précisément parce que la liberté de conscience risque de constituer un obstacle à la paix civile, que Locke fonde son argumentation sur le devoir d'obéir au magistrat et sur la séparation des intérêts temporels et du salut. 
Si l'auteur ne renvoie pas, ou peu, à la source réformée du thème de la liberté de conscience, il en examine en revanche les conséquences dans le corpus philosophique, notamment chez le protestant Pierre Bayle. En faisant de la liberté de conscience la condition même de la connaissance de la vérité et de la pensée, ce dernier érige la lumière naturelle en instance capable de nous révéler le vrai et le juste, c'est-à-dire les règles morales, et ce de manière aussi certaine que si elles étaient des règles de géométrie. Thierry examine le déplacement du statut moral de l'erreur opéré par Bayle, dont le formalisme moral, faisant primer la sincérité sur la vérité et la bonne foi sur la rectitude du dogme religieux, rend légitimes les «droits de la conscience erronée ». La modification des catégories de l'orthodoxie et de l'hérésie permet d'étendre la tolérance aux athées (qui peuvent juger en raison et ne sont plus taxés d'immoralistes et de séditieux) et d'ouvrir le débat au domaine sécularisé des mœurs.

Inaugurée par Locke et poursuivie par Stuart Mill, la tradition libérale pense la tolérance à partir d'une réduction de la sphère publique au profit du développement des formes variées de modes de vie individualisés dans la sphère du privé. La distinction semble donc désormais bien établie entre la valeur d'une croyance et ses effets sur la vie publique. Thierry remarque cependant que les fondements de la liberté individuelle restent ambigus dans la perspective de Stuart Mill. Comment distinguer clairement, en effet, les actions qui ont des effets sur autrui et qui relèvent pour cela d'une codification par l'État, de celles qui n'en ont pas? L'auteur déploie la conception libérale de la tolérance dans le champ des mœurs en analysant les recommandations de la commission chargée en Grande-Bretagne de discuter du statut légal de l'homosexualité et de la prostitution : là où Patrick Devlin refuse de penser une morale privée (les comportements sont privés, tandis que la morale ne vaut que pour une communauté), Stuart Mill fait de la société le seul juge de ses intérêts, qu'elle détermine par l'opinion commune exprimant le jugement du point de vue de l'homme raisonnable. Mais s'il n'y a pas d'autre guide moral en démocratie que la présupposition que les hommes seront capables de juger raisonnablement, le risque est, comme l'avait vu Stuart Mill, que la majorité dicte à chacun sa façon de vivre, constituant une «tyrannie d'un genre nouveau ». Thierry examine enfin les rapports de la pornographie (cas particulier du rapport entre public et privé) et de la démocratie.

Au terme de ce parcours, la liberté de conscience a perdu sa justification instrumentale (la recherche du vrai) pour devenir un principe indépendant de ses contenus affirmant le droit d'un individu sur ses croyances et sur sa vie. Elle est désormais reprise, suivant Patrick Thierry, dans le cadre du communautarisme plutôt que dans celui de l'individualisme. Pour n'être plus pensée comme une concession ou une faiblesse, la tolérance n'en reste pas moins suspendue à un rapport de force. La pensée démocratique hésite ainsi régulièrement encore entre la tolérance et le droit: tandis que la première laisse l'État et le privé à leurs affaires respectives, le droit offre les avantages ambigus de la garantie publique. En se sécularisant, la tolérance est devenue une affaire juridique sans cesser d'être une épreuve morale où se remanient les identités. Si elle reste toujours embarrassée par sa propre justification, le changement n'en est pas moindre : qui tolère peut y trouver un bénéfice.

Julie SAADA-GENDRON 